\title{
ADA2 is a lysosomal DNase regulating the type-I interferon response
}

\author{
Ole Kristian Greiner-Tollersrud ${ }^{1 *}$, Vincent Boehler ${ }^{2 \$}$, Eva Bartok ${ }^{3 \$}$, Máté Krausz ${ }^{4 \$}$, Aikaterini Polyzou ${ }^{5}$, Johanna Schepp ${ }^{4}$, \\ Maximilian Seidl ${ }^{6}$, Jan Ole Olsen ${ }^{1}$, Cristian R. Smulski ${ }^{7}$, Salvatore Raieli ${ }^{8}$, Katrin Hübscher ${ }^{4}$, Eirini Trompouki ${ }^{6}$, Regina Link $^{9}$, \\ Hilmar Ebersbach ${ }^{9}$, Honnappa Srinivas ${ }^{9}$, Martine Marchant ${ }^{9}$, Dieter Staab ${ }^{9}$, Danilo Guerini ${ }^{9}$, Sebastian Baasch ${ }^{4}$, Philipp

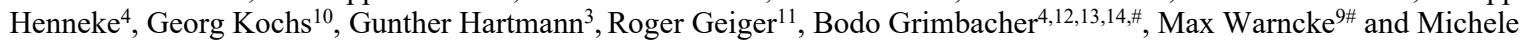 \\ Proietti ${ }^{4,12, \#^{*}}$
}

\section{Affiliations:}

${ }^{1}$ Institute of Medical Biology University of Tromso, Tromso, Norway

${ }^{2}$ Novartis Institutes for Biomedical Research, Basel 4056, Switzerland.

${ }^{3}$ Institut für Klinische Chemie und Klinische Pharmakologie, Universitätsklinikum Bonn, Bonn, Germany

${ }^{4}$ Institute for Immunodeficiency, Center for Chronic Immunodeficiency, Medical Center, Faculty of Medicine, Albert-Ludwigs-University of Freiburg, Germany

${ }^{5}$ Institute of Pathology, Medical Center, Faculty of Medicine, University of Freiburg, Freiburg, Germany.

${ }^{6}$ Max Planck Institute of Immunobiology and Epigenetics, Freiburg, Germany.

${ }^{7}$ Medical Physics Department, Centro Atómico Bariloche, Comisión Nacional de Energía Atómica (CNEA), Consejo Nacional de Investigaciones Científicas y Técnicas (CONICET), Av. E. Bustillo 9500, R8402AGP San Carlos de Bariloche, Río Negro, Argentina.

${ }^{8}$ R\&D Department, BIOGENERA SpA, Bologna, Italy

${ }^{9}$ Novartis Institutes for Biomedical Research, Basel 4056, Switzerland.

${ }^{10}$ Institute of Virology, Medical Centre, Faculty of Medicine, University of Freiburg, Freiburg, Germany

${ }^{11}$ Institute for Research in Biomedicine, Università della Svizzera italiana, Bellinzona, Switzerland

${ }^{12}$ RESIST - Cluster of Excellence 2155 to Hanover Medical School, Satellite Center Freiburg, Germany

${ }^{13}$ CIBSS - Centre for Integrative Biological Signalling Studies, Albert-Ludwigs University, Freiburg, Germany

\$, \# equal contribution

* to whom correspondence shall be addressed michele.proietti@uniklinik-freiburg.de; or ole.k.tollersrud@uit.no 


\begin{abstract}
:
Deficiency of adenosine deaminase 2 (DADA2) is a severe, congenital syndrome, which manifests with hematologic, immunologic and inflammatory pathologies. DADA2 is caused by biallelic mutations in $A D A 2$, but the function of ADA2, and the mechanistic link between ADA2 deficiency and the severe inflammatory phenotype remains unclear. Here, we show that monocyte-derived proteomes from DADA2 patients are highly enriched in interferon response proteins. Using immunohistochemistry and detailed glycan analysis we demonstrate that ADA2 is post-translationally modified for sorting to the lysosomes. At acidic, lysosomal pH, ADA2 acts as a novel DNase that degrades cGAS/Sting-activating ligands. Furthermore, we define a clear structure-function relationship for this acidic DNase activity. Deletion of ADA2 increased the production of cGAMP and type I interferons upon exposure to dsDNA, which was reverted by ADA2 overexpression or deletion of $S T I N G$. Our results identify a new level of control in the nucleic acid sensing machinery and provide a mechanistic explanation for the pathophysiology of autoinflammation in DADA2.
\end{abstract}

\title{
One Sentence Summary:
}

ADA2 is a lysosomal nuclease controlling nucleic acid sensing and type I interferon production.

Introduction:

Deficiency of adenosine deaminase 2 (DADA2) is an autosomal recessive disease characterized by a defective regulation of the inflammatory response $(1,2)$. The disease was first described in 2014 in young patients with a polyarteritis nodosa-like phenotype and biallelic mutations in the $A D A 2$ gene (previously called $C E C R 1$ ). To date, more than 200 DADA2 patients have been reported, and the description of the clinical phenotype has expanded (1-5). DADA2 shares clinical and laboratory signs with type I interferonopathies, a group of genetically heterogeneous disorders characterized by autoinflammation and constitutive activation of the antiviral type I interferon (IFN) response. However, how ADA2 regulates the immune response is currently unknown $(6)$.

Adenosine deaminases (ADA) are generally accepted to be essential for the metabolism and neutralization of purine nucleosides, respectively ADA1 within the intracellular and ADA2 within the extracellular space. However, in comparison to ADA1, ADA2 has a low affinity for adenosine (Ado) and 2'-deoxyadenosine (dAdo) $(\mathrm{Km} \sim 2 \mathrm{mM})$ and the adenosine concentration in the extracellular space is 10,000 fold less than its $\mathrm{Km}$ value $(\sim 0.2 \mu \mathrm{M})(7-10)$. Accordingly, the biological relevance of the ADA2 deaminase activity is a matter of current debate. Furthermore, while ADA1 is ubiquitously expressed (11), ADA2 is preferentially expressed in monocytes and macrophages (12-14) (Fig. 1A-B). Altogether these observations raise the possibility that ADA2 has a distinct function, unrelated to its adenosine deaminase activity.

To gain insight into the molecular consequences of ADA2 deficiency, we compared the proteomes of purified monocytes from six patients with different biallelic mutations in $A D A 2$ (suppl. Fig. 1A-B) to sex- and age-matched controls. At a false discovery rate of $1 \%$, we identified more than 10,000 different proteins with an average of 7,500 proteins per sample. 138 
proteins were significantly ( $\log 2$ fold change cut-off of 1.5 and Welch's test $p$-value $<=0.05$ ) upregulated and 79 proteins were downregulated in DADA2 patients compared to healthy individuals (Fig. 1C and Table S1). As expected, ADA2 was undetectable or strongly reduced in all proteomes from DADA2 patients (Fig. 1D). Pathways analysis of differentially expressed proteins revealed a remarkable up-regulation of interferon signaling-related pathways in DADA2 patients compared to controls (Fig 1E). Network analysis suggested that ADA2 deficiency mostly affected the innate immune response to viral infection (Fig. 1F). Differentially-expressed proteins comprised several interferon-stimulated genes (ISGs) $(18,9)$, including guanylate binding proteins (GBP5, GBP4, GBP1 and GBP2), interferon-induced proteins with tetratricopeptide repeats (IFIT1 and IFIT3), 2'-5'-oligoadenylate synthase 3 (OAS3), signal transducer and activator of transcription 1 alpha/beta (STAT1), and the interferon-induced GTPbinding protein Mx1 (Fig. 1G). Proteins previously associated with interferonopathy (8-9, 1921), were expressed at regular levels (Fig. S1C), supporting the growing consensus that DADA2 is a distinct clinical entity (15). Comparing ADA2null (no ADA2 protein detectable) and ADA2dim (residual ADA2 protein detectable) patients, we observed a significant (unpaired t.test $<0.01 \&$ nonlinear fit R Square $>0.9$ ) correlation between the ADA2 expression and the interferon signature (Fig. S2A). These data suggested that ADA2 directly controls the antiviral state acting as a rheostat of the type I interferon signature in monocytes.

To address whether the observed interferon signature was cell intrinsic, we generated an ADA2deficient monocytic cell line (THP-1) (Fig. S3A-b). Wild-type and ADA2-deficient cells were subsequently tested by real-time-PCR for the expression of several interferon induced genes (ISGs), namely IFI16, IFI27, IFI44, IFIT1, IFNB1, ISG15, RSAD2, SIGLEC1 and CXCL8 (16). As shown in Fig. 1H, ADA2-deficient cells showed increased expression of all the measured ISGs. We also observed increased levels of secreted CXCL10, another interferon-induced protein, in the supernatants of ADA2-deficient THP-1 (Fig. 1I). Importantly, ADA2 reexpression by lentiviral transduction completely reverted the phenotype (Fig. 1L). Collectively, these data indicate that ADA2 negatively regulates the type 1 interferon pathway in monocytes in a cell-intrinsic manner.

Current consensus considers ADA2 to be a predominantly extracellular protein $(17,18)$. However, our monocyte data above suggested an intrinsic function for ADA2, inconsistent with an extracellular adenosine deamination. We were particularly interested in understanding the cellular and subcellular expression pattern on ADA2 within secondary lymphoid organs, in which we (19) (Fig. S4A-F) have observed significant histopathological abnormalities in DADA2 patients. To address this question, we stained human tonsils for ADA2. ADA2 signal was confined to germinal centers and was mostly expressed in tingible body macrophages (Fig. S4 G, H). Interestingly, at high magnification, ADA2 was observed in vesicular structures resembling phagolysosomes (Fig. 2A). To address whether ADA2 was indeed present in lysosomal vesicles, we additionally stained tonsil sections with LAMP-1, a marker for lysosomal membranes. Immunofluorescence confirmed that ADA2 is contained within the lumen of LAMP1-positive lysosomal vesicles (Fig. 2B and inlet).

In order to be targeted to the lysosome, soluble proteins typically need to be tagged with mannose-6-phosphate (M6P) on a subset of their N-glycans, which are recognized by the mannose-6-phosphate sorting receptor in the trans-Golgi (20) (Fig. 2C). Once in the lysosomes, these glycan structures are intensively trimmed by lysosomal phosphatase and exoglycosidases. To confirm that ADA2 is a lysosomal protein and to understand how it is targeted to these 
cellular organelles in vivo, we analyzed the glycosylation pattern of endogenous ADA2. Except in rodents, ADA2 orthologs are present in all mammals, including pigs, which exhibits a high similarity with human ADA2 (Fig. S5A-B). Further, analysis of public datasets showed that ADA2 is highly expressed by microglia (21) (Fig. S5C). Thus, to access sufficient material for glycoanalysis, we purified ADA2 from porcine brain (Fig. S6A-D). Data are available via ProteomeXchange (22) with identifier PXD019373. We found that endogenous ADA2 contains a high proportion of M-6 phosphorylated glycans linked to three of its glycosylation sites (N127, and N378). The spectrum of glycan structures in ADA2 overlaps with the lysosomally-trimmed glycans of known lysosomal proteins, such as lysosomal alpha-mannosidase (LAMAN), phospholipase D3 (PLD3) and ependymin related protein 1 (EPDR1), and it is different from the glycan structures of the extracellular proteins oligodendrocyte myelin glycoprotein (OMgp) and signal regulatory protein alpha (Sirpa) (Fig. 2D). Altogether, these data indicate that in monocytes/macrophages ADA2 is targeted to the lysosomes via the M6P-dependent pathway.

Since the adenosine deaminase activity of ADA2 is incompatible with the acidic-lysosomal $\mathrm{pH}$ (18), these results reinforced the notion that in the lysosome ADA2 serves a distinct function, unrelated to its deaminase activity. In agreement with this, there are clear differences in the clinical phenotypes of ADA1 vs. ADA2 deficiency (Table S2), while DADA2 shares clinical and immunological similarities with other type I interferonopathies (23-25). Of particular relevance to this study, there is a substantial clinical overlap of DADA2 with DNase type II deficiency (24) (Table S2), raising the question of whether ADA2 is involved in DNA sensing.

To search for a new function of the protein we evaluated the differences between the active site of ADA1 and ADA2 (16). Although both enzymes accommodate a purine in the active site pocket, ADA2 possesses an enlarged pocket allowing the positioning of a purine-linked ribose unit $(17,18)$. This "widening" of the active site may allow a larger nucleotide-containing molecule, such as DNA or RNA, to serve as a substrate for ADA2. This observation, together with the clinical similarities between DADA2 and DNase2 deficiency, led us to hypothesize that ADA2 could possess a hitherto undescribed DNase function. Furthermore, given its lysosomal localization, we considered the possibility that a putative DNase activity of ADA2 could be $\mathrm{pH}$ dependent. Accordingly, when we incubated endogenous porcine ADA2 with plasmid DNA, the plasmid was degraded with a $\mathrm{pH}$ optimum between 4.6 and 5, corresponding to the lysosomal $\mathrm{pH}$ (Fig. 3A), but not at neutral pH. More detailed investigations revealed that, at low concentrations of ADA2, the supercoiled plasmid DNA was converted into a relaxed circular molecule, while at a higher concentration of ADA the relaxed circular plasmid was converted into a linear form, and smaller DNA fragments appeared (Fig 3B). These results suggest that ADA2 acts as a nicking endonuclease. Any contamination with the only currently known lysosomal DNase, DNase 2, was ruled out by the separation of ADA2 from DNase 2 on hydroxyapatite chromatography (Fig. S4B). Data are available via ProteomeXchange (22) with identifier PXD019373.

To validate these observations, we expressed and purified recombinant human ADA2 from HEK cells and measured its nuclease activity using a FRET-based assay. This assay confirmed the

40 DNase activity of recombinant ADA2, as well its maximal activity at lysosomal pH (Fig. 3C).

The DNase activity of ADA2 inversely correlated with the salt concentration (Fig. 3C), similar to DNase type I (26). Importantly, MS/MS analysis of our recombinant ADA2 did not detect any contamination by known nucleases (Fig. S7A). Data are available via ProteomeXchange (22) with identifier PXD019382. Modeling of the binding of ADA2 with double-stranded DNA suggested that the $\mathrm{a} \sim 40$ amino acid domain called PRB domain (Fig. 3D), which is present in 
ADA2, but absent in ADA1 (26), mediates the interaction between the protein and the dsDNA molecule (Fig. 3E). In agreement, ADA1 lacked nuclease activity (Fig. 3G, H). These results provide a mechanistic explanation of the stark clinical differences between ADA1 and ADA2 deficiency.

To gain further insight into the structure-function relationship between ADA2 and DNase activity, we selected variants of ADA2 that cause defined clinical phenotypes (27) and were predicted to be important for ADA2 DNase activity by structural modeling (Table S.3 and Fig. S7B). These variants were then expressed in HEK cells, purified, and tested for DNase and deaminase activity. Of note, many of the single point mutants and domain deletions, including the PRB domain, showed a severe loss of expression, indicating that these residues are essential for the protein stability (Table S.3). Nevertheless, eight mutants had a sufficient expression for further analysis of enzymatic activity. Evaluation of adenosine deamination versus DNase activity revealed a strong correlation between the two (Fig. 3F), with the adenosine deamination correlating well with values reported previously for these variants (27) (Fig. 3F). To further validate these findings, we selected ten variants for larger scale production and stringent purification. The stringently purified proteins fully confirmed the results from the smaller scale screen (Fig. S7C). Importantly, we detected variants, like G358R, which showed absent or largely reduced ADA (27) and DNase activity. (Fig 3G-H). The G358R amino acid change replaces an highly conserved glycine with arginine at position 358 of the ADA2 protein (p.Gly358Arg) and it has been reported in homozygosity or in combination with another ADA2 variant (compound heterozygosity) in individuals with DADA2 and bone marrow pathology (27-30).

Collectively, our data suggest that ADA2 deficiency could lead to a defective degradation of double-stranded DNA, which would be expected to provide more ligands for DNA-sensing machinery, in particular the cGAS-STING pathway. Alternatively, ADA2 deficiency may more generally elicit monocytes sensitivity to type I interferon stimulants, via an unknown mechanism unrelated to its DNase activity. To directly address these hypotheses, we measured type I IFN in the supernatants of ADA2 KO monocytic cells following stimulation with different pattern recognition receptor agonists. Specifically, cells were stimulated with: Poly-IC, LPS, R-837 or interferon stimulatory DNA. Poly-IC is a synthetic RNA analogous sensed by three receptors: TLR3, that signals through adapter Toll/IL-1R domain-containing adapter-inducing IFN- $\beta$ (TRIF); and two cytoplasmic receptors, retinoic acid-inducible gene I (RIG-I) and melanoma differentiation-associated protein-5 (MDA-5), which both signal through mitochondrial antiviral-signaling protein (MAVS); LPS, is an agonist of the TLR4, which signals through MyD88; R-837 is, an imidazoquinoline amine analog to guanosine, sensed by the TLR7; interferon stimulatory DNA, a dsDNA oligomer that, when transfected into various cell types, including macrophages, activates the cGAS-STING pathway (31). ADA2 deficiency did not affect type I interferon production in response to Poly-IC, LPS or R-837 (Fig. 4A). In contrast, we observed an increased induction of interferon when ADA2-deficient cells were exposed to interferon stimulatory DNA (Fig. 4B). This difference was reverted by the over-expression of wild-type ADA2 and by the genetic deletion of STING (Fig. 4B). These data strongly suggest that ADA2 deficiency determines a defective sensing of dsDNA and a subsequent hyperactivation of STING signaling. In agreement with this, STING deletion also completely reverted the interferon signature (Fig. 4C) and CXCL10 secretion (Fig. 4D) in ADA2 KO monocytic cells. Deletion of the critical TLR adaptor protein MyD88 or the intracellular dsRNA sensor MAVS did not affect the interferon signature of ADA2-deficient cells, further supporting 
the hypothesis that this interferon response is dsDNA-cGAS-STING-dependent (Fig. 4C, D). STING is activated by cGAMP, a cyclic dinucleotide that is produced by cGAS upon DNA stimulation (32). Thus, intracellular cGAMP levels correlate with the level of dsDNA detected by cGAS (33). We therefore measured intracellular cGAMP in wild-type and ADA2 KO monocytic cells following stimulation with dsDNA. As shown in Fig. 4E, ADA2 deficiency was associated with a significant increase in the production of cGAMP, which could be reverted by the over-expression of ADA2 (Fig. 4E).

In summary, our discovery of the lysosomal localization and the unique structure of ADA2 together with the severe interferonopathy observed in DADA2 patients with clinical similarities to DNase2 deficiency led us to the discovery of a hitherto unappreciated DNase function of ADA2. This function has presumably escaped prior detection due to its unique dependence upon acidic, lysosomal $\mathrm{pH}$. Building on the DNase function, we have established that ADA2 is essential for the tuning of nucleic acid sensing in myeloid cells with a remarkable specificity for the cGAS-STING pathway. These data strongly suggest that altered degradation of dsDNA is the primary driver of the interferonopathy observed in DADA2 patients. Our results reveal a novel level of control in nucleic acid sensing and not only provide important mechanistic insight into the pathogenesis of ADA2 deficiency and putatively more common and complex autoinflammatory conditions such as lupus erythematosus or vasculitis, but additionally opens the horizon for the development of personalized treatment approaches for these conditions.

\section{References and Notes:}

1. P. Navon Elkan et al., Mutant Adenosine Deaminase 2 in a Polyarteritis Nodosa Vasculopathy. N. Engl. J. Med. 370, 921-931 (2014).

2. Q. Zhou et al., Early-Onset Stroke and Vasculopathy Associated with Mutations in ADA2. N. Engl. J. Med. 370, 911-920 (2014).

3. R. Caorsi et al., Prevalence of CECR1 mutations in pediatric patients with polyarteritis nodosa, livedo reticularis and/or stroke. Pediatr. Rheumatol. 13, 87 (2015).

4. J. Schepp et al., Screening of 181 Patients With Antibody Deficiency for Deficiency of Adenosine Deaminase 2 Sheds New Light on the Disease in Adulthood. Arthritis Rheumatol. 69, 1689-1700 (2017).

5. S. Nanthapisal et al., Deficiency of Adenosine Deaminase Type 2: A Description of Phenotype and Genotype in Fifteen Cases. Arthritis Rheumatol. 68, 2314-2322 (2016).

6. H. J. Schrader, W. P., Pollara, B. \& Meuwissen, W. P. Schrader, B. Pollara, H. J. Meuwissen, Characterization of the residual adenosine deaminating activity in the spleen of a patient with combined immunodeficiency disease and adenosine deaminase deficiency. Proc. Natl. Acad. Sci. U. S. A. 75, 446-50 (1978).

7. A. V. A. V. Zavialov et al., Human adenosine deaminase 2 induces differentiation of monocytes into macrophages and stimulates proliferation of $\mathrm{T}$ helper cells and macrophages. J. Leukoc. Biol. 88, 279-290 (2010). Deaminase 2 (DADA2), an Inherited Cause of Polyarteritis Nodosa and a Mimic of Other Systemic Rheumatologic Disorders. Curr. Rheumatol. Rep. 19, 70 (2017). 
9. C. Azzari, G. la Marca, M. Resti, Neonatal screening for severe combined immunodeficiency caused by an adenosine deaminase defect: a reliable and inexpensive method using tandem mass spectrometry. J. Allergy Clin. Immunol. 127, 1394-9 (2011).

10. L. Van Eyck et al., Hematopoietic stem cell transplantation rescues the immunologic phenotype and prevents vasculopathy in patients with adenosine deaminase 2 deficiency. J. Allergy Clin. Immunol. 135, 283-287.e5 (2015).

11. C. Gakis, Adenosine deaminase (ADA) isoenzymes ADA1 and ADA2: Diagnostic and biological role. Eur. Respir. J. 9, 632-633 (1996).

12. B. A. Conlon, W. R. Law, Macrophages are a source of extracellular adenosine deaminase-2 during inflammatory responses. Clin. Exp. Immunol. 138, 14-20 (2004).

13. H. Ratech, F. Martiniuk, W. Z. Borer, H. Rappaport, Differential expression of adenosine deaminase isozymes in acute leukemia. Blood. 72, 1627-1632 (1988).

14. S. Iwaki-Egawa, T. Yamamoto, Y. Watanabe, Human plasma adenosine deaminase 2 is secreted by activated monocytes. Biol. Chem. 387, 319-321 (2006).

15. L. Moens, M. Hershfield, K. Arts, I. Aksentijevich, I. Meyts, Human adenosine deaminase 2 deficiency: A multi-faceted inborn error of immunity. Immunol. Rev. 287, 62-72 (2019).

16. G. I. Rice et al., Assessment of Type I Interferon Signaling in Pediatric Inflammatory Disease. J. Clin. Immunol. 37, 123-132 (2017).

17. A. V. Zavialov, X. Yu, D. Spillmann, G. Lauvau, A. V. Zavialov, Structural basis for the growth factor activity of human adenosine deaminase ADA2. J. Biol. Chem. 285, 1236712377 (2010).

18. A. V. Zavialov, Å. Engström, Human ADA2 belongs to a new family of growth factors with adenosine deaminase activity. Biochem. J. 391, 51-57 (2005).

19. J. Schepp et al., Deficiency of Adenosine Deaminase 2 Causes Antibody Deficiency. $J$. Clin. Immunol. 36, 179-186 (2016).

20. T. Braulke, J. S. Bonifacino, Sorting of lysosomal proteins. Biochim. Biophys. Acta-Mol. Cell Res. 1793, 605-614 (2009).

21. N. G. Skene et al., Genetic identification of brain cell types underlying schizophrenia. Nat. Genet. 50, 825-833 (2018).

22. Y. Perez-Riverol et al., The PRIDE database and related tools and resources in 2019: Improving support for quantification data. Nucleic Acids Res. (2019), doi:10.1093/nar/gky1106.

23. M. P. Rodero, Y. J. Crow, Type I interferon-mediated monogenic autoinflammation: The type I interferonopathies, a conceptual overview. J. Exp. Med. 213, 2527-2538 (2016).

24. C. Y. Rodero MP, Tesser A, Bartok E, Rice GI, Della Mina E, Depp M, Beitz B, Bondet V, Cagnard N, Duffy D, Dussiot M, Frémond ML1, Gattorno M, Guillem F, Kitabayashi N, Porcheray F, Rieux-Laucat F, Seabra 1, Uggenti C, Volpi S, Zeef LAH, Alyanakian MA, Beltrand et al., Type I interferon-mediated autoinflammation due to DNase II deficiency. Nat. Commun. 8, 2176 (2017).

25. S. Kretschmer, M. A. Lee-Kirsch, Type I interferon-mediated autoinflammation and 
autoimmunity. Curr. Opin. Immunol. 49 (2017), pp. 96-102.

26. C. Q. Pan, R. A. Lazarus, Hyperactivity of human DNase I variants: Dependence on the number of positively charged residues and concentration, length, and environment of DNA. J. Biol. Chem. 273, 11701-11708 (1998).

27. P. Y. Lee et al., Genotype and functional correlates of disease phenotype in deficiency of adenosine deaminase 2 (DADA2). J. Allergy Clin. Immunol. (2020), doi:10.1016/j.jaci.2019.12.908.

28. H. Hashem et al., Successful reduced intensity hematopoietic cell transplant in a patient with deficiency of adenosine deaminase 2. Bone Marrow Transplant. 52, 1575-1576 (2017).

29. J. C. Ulirsch et al., The Genetic Landscape of Diamond-Blackfan Anemia. Am. J. Hum. Genet. 103, 930-947 (2018).

30. C. Carmona-Rivera et al., Deficiency of adenosine deaminase 2 triggers adenosinemediated NETosis and TNF production in patients with DADA2. Blood. 134, 395-406 (2019).

31. L. Unterholzner et al., IFI16 is an innate immune sensor for intracellular DNA. Nat. Immunol. 11, 997-1004 (2010).

32. L. Sun, J. Wu, F. Du, X. Chen, Z. J. Chen, Cyclic GMP-AMP synthase is a cytosolic DNA sensor that activates the type I interferon pathway. Science (80-. ). 339, 786-791 (2013).

33. X. Li et al., Cyclic GMP-AMP Synthase Is Activated by Double-Stranded DNA-Induced Oligomerization. Immunity. 39, 1019-1031 (2013).

34. W. Xu et al., Mapping of $\gamma / \delta \mathrm{T}$ cells reveals $\mathrm{V} \delta 2+\mathrm{T}$ cells resistance to senescence. EBioMedicine. 39, 44-58 (2019).

35. B. Assembly, P. Citation, M. Description, M. P. Annotations, The crystal structure of human adenosine deaminase. 10.2210/pdb3IAR/pdb, 9-10 (2011).

Acknowledgments: We are deeply grateful to all affected individuals, their families and all healthy donor controls who participated in this study. We thank Pavla Mrovecova, Mary Buchta, Hanna Haberstroh, Nadine Glaser (CCI, Uniklinik Freiburg), and Thi-Thanh-Thao Tran (Novartis) for their excellent technical assistance. We thank Prof. Dr. Martin Schwemmle for providing SC35M encoding GFP. We thank Prof. Dr. Stephan Ehl (CCI, Uniklinik Freiburg), Ben Roediger (Novartis) and Dr. Elisabetta Traggiai (Novartis) for helpful advice and discussion. Some samples have been taken from the CCI-biobank, a partner of the Freeze Biobank Freiburg.

Funding: Financial support for this research came from the German Ministry of Education and Research (BMBF, grant \#), CCI Modul 4ap11, Thyssen (Thyssen grant - 10.18.1.039MN). BG receives support through the Deutsche Forschungsgemeinschaft (DFG) SFB1160/2_B5, under Germany's Excellence Strategy (CIBSS - EXC-2189 - Project ID 390939984, and RESIST EXC 2155 - Project ID 39087428); through the E-rare program of the EU, managed by the DFG, grant code GR1617/14-1/iPAD; and through the „Netzwerke Seltener Erkrankungen“ of the 
German Ministry of Education and Research (BMBF), grant code: GAIN_01GM1910A. This work was supported in part by the Center for Chronic Immunodeficiency (CCI), Freiburg Center for Rare Diseases (FZSE). ET and AP were funded by the Deutsche Forschungsgemeinschaft, Research Training Group GRK2344 „MeInBio - BioInMe“. The funding organizations had no role in study design, the collection, analysis and interpretation of data, the writing of the report, nor the decision to submit the paper for publication.

Author contributions: Conceptualization: O.K.G.T., B.G., M.W., E.B., C.R.S, G.H, M.H., and M.P.. Methodology: O.K.G.T., R.G., C.R.S., M.S., A.P. M.W. and M.P.. Validation: O.K.G.T., M.W., B.G. and M.P.. Formal Analysis: M.P., M.W. and A.P.. Investigation: O.K.G.T., M.K., M.S., S.B., C.R.S., M.S., K.H., J.S., H.E., S.B., M.M., V.B., M.B., D.S., N.J.G, D.G., M.W. and M.P. Resources: O.K.G.T., M.W., B.G., J.S., A.P. and M.P.. Data Curation: A.P, M.W. and M.P. Writing: O.K.G.T., M.W., B.G., and M.P.. Visualization: O.K.G.T., M.W. and M.P.. Supervision: M.P. O.K.G.T., B.G., M.W.. Funding Acquisition: O.K.G.T., E.T., B.G. and M.P.

Competing interests: The authors declare no competing interests or conflict of interest. 


\section{Figure Legends}

Fig. 1: DADA2 proteomic signature of peripheral monocytes.

(A) ADA2 expression in $\mathrm{CD} 19^{+}, \mathrm{CD}^{+}$, neutrophils and $\mathrm{CD} 14^{+}$immune cell subtypes FACS sorted from peripheral blood or bone marrow of healthy donors detected by immunofluorescence. (B) Analysis of ADA2 expression in different immune cells subtypes analyzed from GSE107011 RNAseq dataset (34). (C) Volcano plot showing differentially regulated (red $=$ up-regulated, blue $=$ down-regulated) proteins in monocytes proteomes of DADA2 patients in comparison to age and sex-matched healthy donors. (D) ADA2 protein amount, as measured by Label Free Quantification (LFQ intensity) in proteomes from DADA2 patients (left) and healthy controls (right). (E) Pathway analysis showing enrichment of interferon and related pathways in DADA2 proteomes compared to controls. (F) Interaction network on the pathways analysis above. $(\mathrm{G})$ Heatmap showing proteins differentially expressed in DADA2 monocytes with respect to controls. In red are highlighted proteins involved in the interferon response (H) RNA expression of 9 interferon induced genes as measured by realtime PCR in $A D A 2^{-/-}$and WT THP-1 cells. Heatmap is showing the log 2 of the fold change ( $A D A 2^{-/-}$vs WT ratio). (I) Measurement of CXCL10 concentration in the supernatant of $A D A 2^{-/-}$and WT THP-1 cells measured by ELISA. The lines over the bars show the statistical comparisons reported in the figure ( 3 independent experiments, each experiment with duplicates; test used, unpaired two tailed t test with Welch's correction, $* * *=p<=0.001$ ). (J) RNA expression of 8 interferon induced genes as measured by realtime PCR in $A D A 2^{--}$and WT THP-1 cells transduced with lentiviruses carrying human ADA2 or the corresponding empty lentivirus. Y axis shows the log. of the Delta $\mathrm{Ct}$ relative to HPRT. The lines over the bars show the statistical comparisons reported in the figure ( 3 independent experiments, each experiment with duplicates; test used, unpaired two tailed t test with Welch's correction, $* *=\mathrm{p}<=0.001, * * *=\mathrm{p}<=0.001, * * * *=\mathrm{p}$ $<=0.0001)$.

\section{Fig.2: Localization of ADA2 in the lysosomes of tingible body macrophages and ADA2 lysosomal targeting via the mannose-6-phosphate dependent pathway.}

(A) ADA2 staining (Blue) in tingible body macrophages. On the right panels the arrows indicate ADA2 positive cellular organelles resembling phagolysosome (B) Immunofluorescence of human tonsils showing LAMP1 positive lysosomes containing ADA2, the inlets show higher (40X) magnification; (C) Diagram showing lysosomal sorting of Mannose-6-phosphorylated proteins (D) Heatmap showing the comparison of the glycan structures linked to specific glycosylation sites of pbADA2 and to other known lysosomal (green) and extracellular (black) proteins. All the proteins have been purified from porcine brain. The color scale represents the percentage of the identified glycan structures (Fig. S4) linked to the indicated amino acid residues.

\section{Fig. 3: Acidic DNase activity of porcine and human ADA2.}

(A-B) Gel electrophoresis showing DNA degradation after 20' incubation of plasmid DNA with pbADA2 at different $\mathrm{pH}(\mathrm{A})$ or at $\mathrm{pH} 4.5$ and different protein concentrations (B). (C) DNase activity of recombinant human ADA2 $(25 \mu \mathrm{g} / \mathrm{ml})$ as measured by FRET assay evaluated at 20' and at different $\mathrm{pH}$ and $\mathrm{NaCl}$ concentration. (D) Modeling of the binding between dsDNA and 
human ADA2 (PDB entry: 3LGD) (17). The top scored model corresponds to the interaction of the dsDNA molecule with the PRB domain, which is located close to the active site and therefore places the DNA molecule on top of the catalytic cleft. (E) Comparison between the ADA1 (PDB entries: 3IAR) (35), and ADA2 (3LGD) structure showing the absence of a $\sim 40$ amino acids insertion (aa 111-147), corresponding to the PRB domain in ADA1 in comparison to ADA2. (F) Evaluation of DNase and ADA activities of 8 recombinant ADA2 mutants and correlation. In green is reported the mutant (G358R) selected for further large-scale validation, in blue the human wild type ADA2. (G-H) Evaluation of DNase and ADA activities of the recombinant G358R mutant, ADA1 and ADA2 and the control His-tagged protein.

\section{Fig. 4: ADA2 dependent cGAS/STING signaling}

(A) Concentration of type I interferon, as measured by HEK-Blue IFN- $\alpha / \beta$ report assay, in the supernatant of WT (white), $A D A 2^{-/-}$(blue) and $A D A 2^{-/-}$lentiviral transduced with human ADA2 (red) THP-1 cells, after overnight stimulation with PolyIC, LPS or Imiquimod. The lines over the bars show the groups compared for statistical analysis ( 2 independent experiments, each experiment with triplicates; test used, unpaired two tailed t test, n.s = not significant). (B) Concentration of type I interferon, as measured by HEK-Blue IFN- $\alpha / \beta$ report assay, in the supernatant of WT (white), $A D A 2^{-/-}$(blue) and $A D A 2^{-/-}$lentiviral transduced with human ADA2

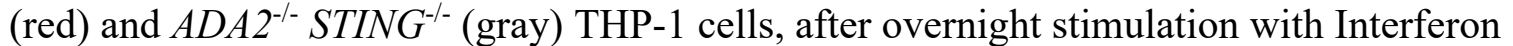
Stimulating DNA (ISD). The lines over the bars show the statistical comparisons reported in the figure ( 3 independent experiments, each experiment with triplicates; test used, unpaired two tailed t test with Welch's correction, $* * *=\mathrm{p}<=0.001, * * * *=\mathrm{p}<=0.0001$ ). (C) Expression of 9 interferon stimulated genes measured by RT-PCR in unstimulated WT, $A D A 2^{-/-}, A D A 2^{-/} S T I N G^{-/-}$ , $A D A 2^{-/-} M A V S^{-/-}, A D A 2^{-/-} M y d 88^{-/-}$THP-1 cells. Y Axis shows the log of the Delta Ct relative to HPRT. The lines over the bars show the groups compared for statistical analysis (3 independent experiments, each experiment with duplicates; test used, unpaired two tailed t test with Welch's correction, $* * *=\mathrm{p}<=0.001, * * * *=\mathrm{p}<=0.0001$ ). (D) Concentration of CXCL10 in the supernatant of unstimulated WT, $A D A 2^{-/-}, A D A 2^{-/-} S T I N G^{-/-}, A D A 2^{-/-} M A V S^{-/-}, A D A 2^{-/-} M y d 88^{-/-}$ THP-1 cells, measured by ELISA ( 3 independent experiments, each experiment with duplicates; test used, unpaired $\mathrm{t}$ test with Welch's correction, $* * *=\mathrm{p}<0.001$, $* * * *=\mathrm{p}<0.0001)$. (E) cGAMP production in WT, $A D A 2^{-/-}$and $A D A 2^{-/-}$lentiviral transduced with human ADA2 after exposure to dsDNA. 
bioRxiv preprint doi: https://doi.org/10.1101/2020.06.21.162990; this version posted June 22, 2020. The copyright holder for, this preprint

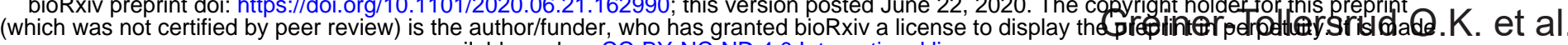
available under aCC-BY-NC-ND 4.0 International license.

Figure 2

A

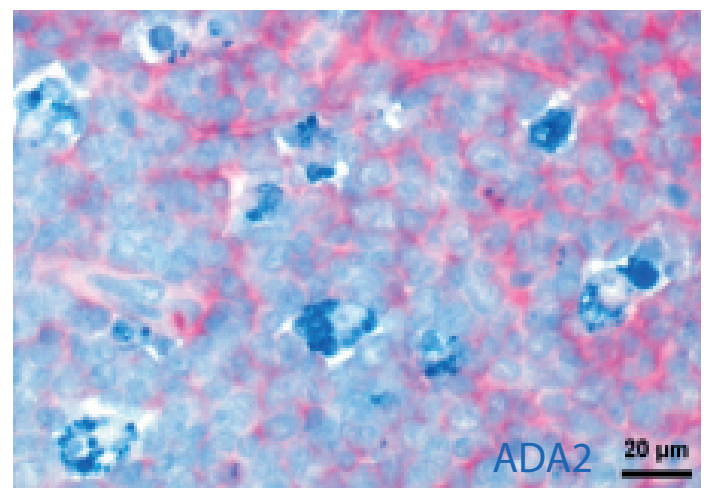

C
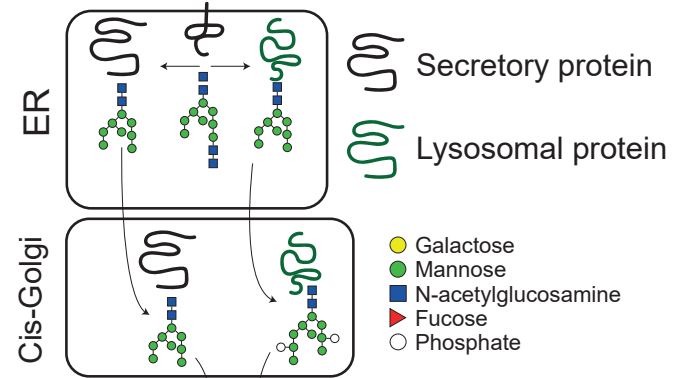

Galactose

Mannose

- N-acetylglucosamine

$\checkmark$ Fucose

Phosphate

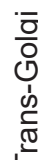

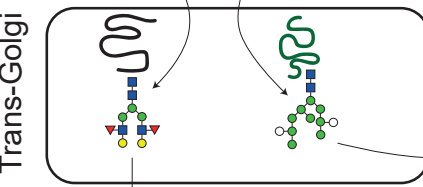

$\ln 20$
B
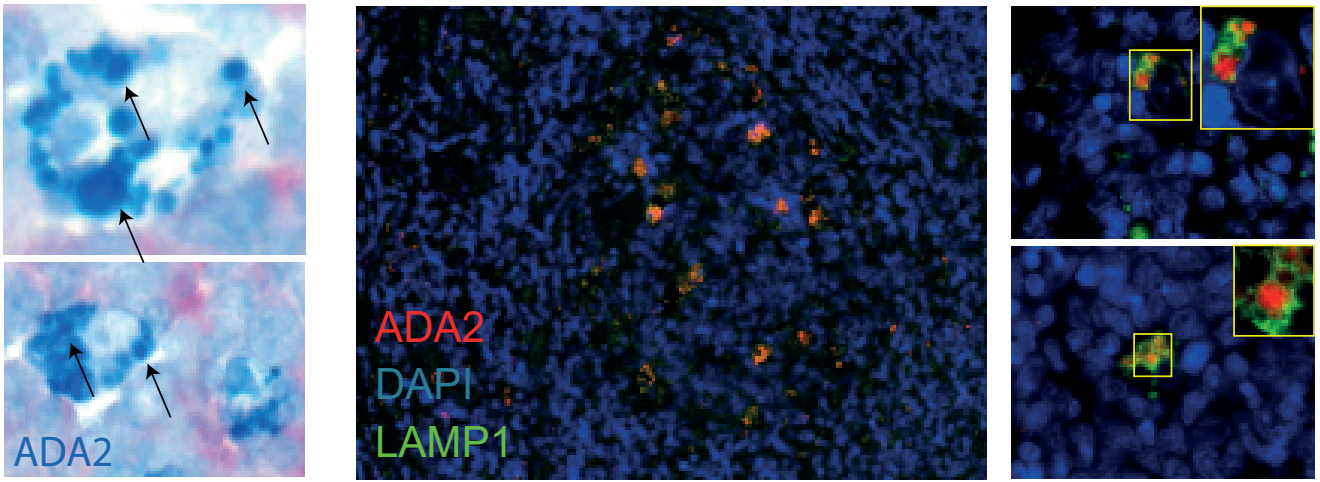

Galactose

O Mannose

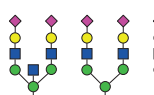

Extracellular proteins

重

SN3 SN2 SN1 NN3 NN2 NN1 LMF

OMgp-N237

Sirpa-N182

Sirpa-N346

PLD3-N385

PLD3-N210

EPDR1-N150

LAMAN-N133

LAMAN-N367

LAMAN-N766

ADA2-N127

ADA2-N174

ADA2-N378

\begin{tabular}{|l|l|l|l|l|l|l|l|l|l|l|l|}
\hline & & & & & & & & & & & \\
\hline & & & & & & & & & & & \\
\hline & & & & & & & & & & & \\
\hline & & & & & & & & & & & \\
\hline & & & & & & & & & & & \\
\hline & & & & & & & & & & & \\
\hline & & & & & & & & & & & \\
\hline & & & & & & & & & & & \\
\hline & & & & & & & & & & & \\
\hline & & & & & & & & & & & \\
\hline & & & & & & & & & & & \\
\hline
\end{tabular}

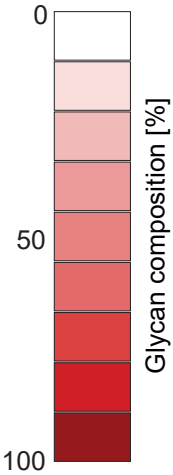


bioRxiv preprint doi: https://doi.org/10.1101/2020.06.21.162990; this version posted June 22, 2020. The copyright holderfor,this preprint

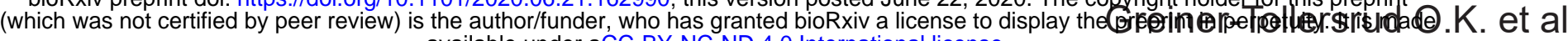
available under aCC-BY-NC-ND 4.0 International license.

Figure 3

A

B

$$
\mathrm{pH}
$$

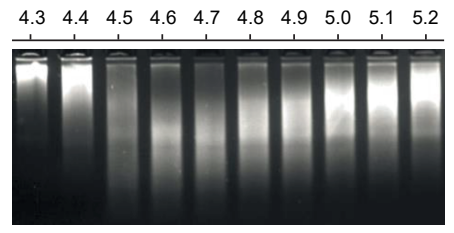

E

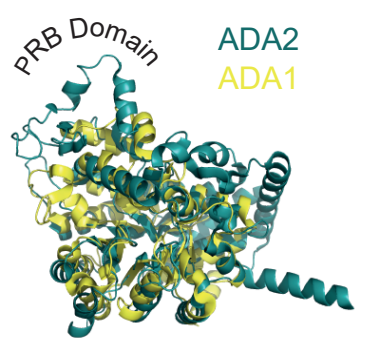

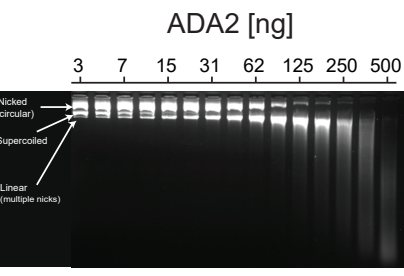

F

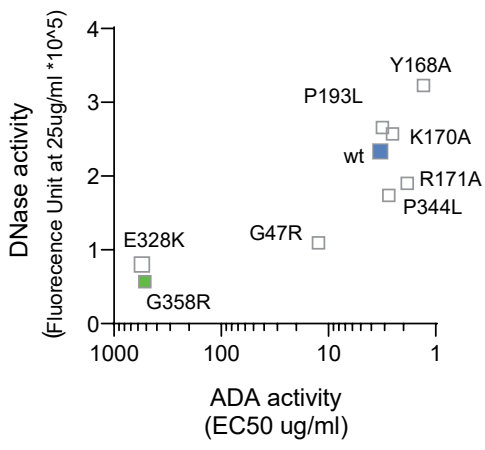

C

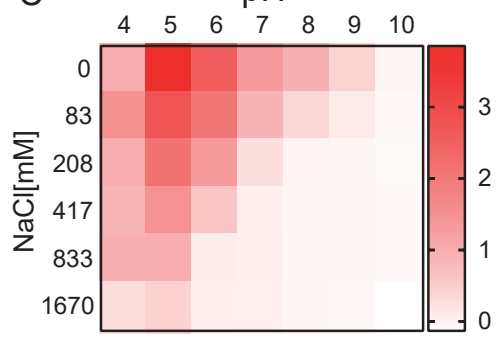

D

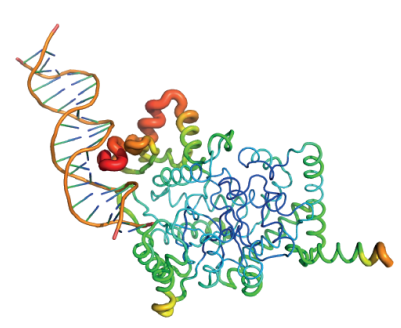

G

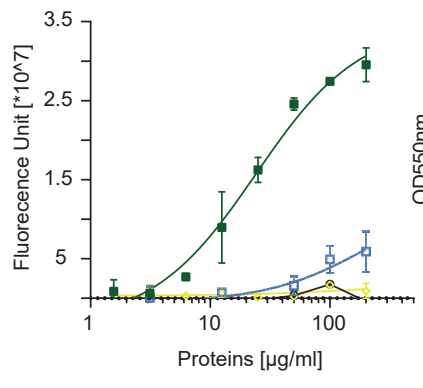

H
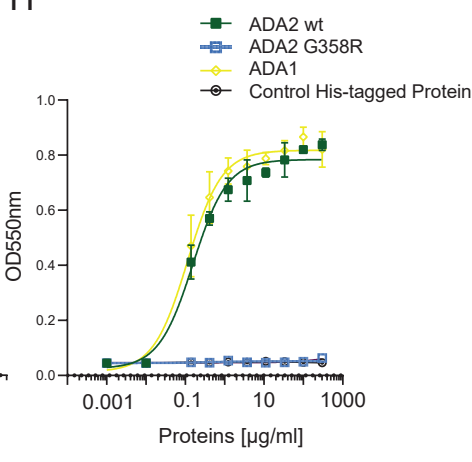
bioRxiv preprint doi: https://doi.org/10.1101/2020.06.21.162990; this version posted June 22, 2020. The copyright holder for this preprint

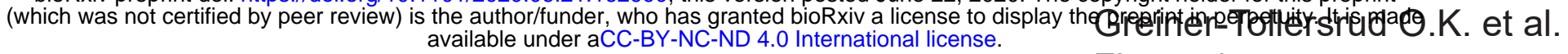

Figure 4

A
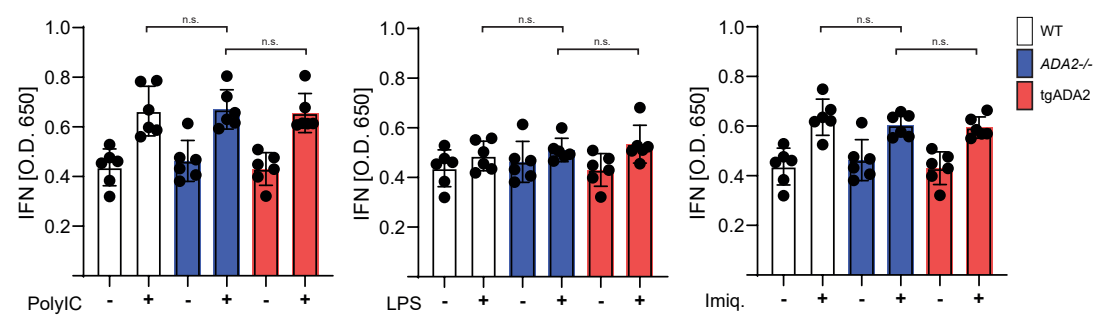

C
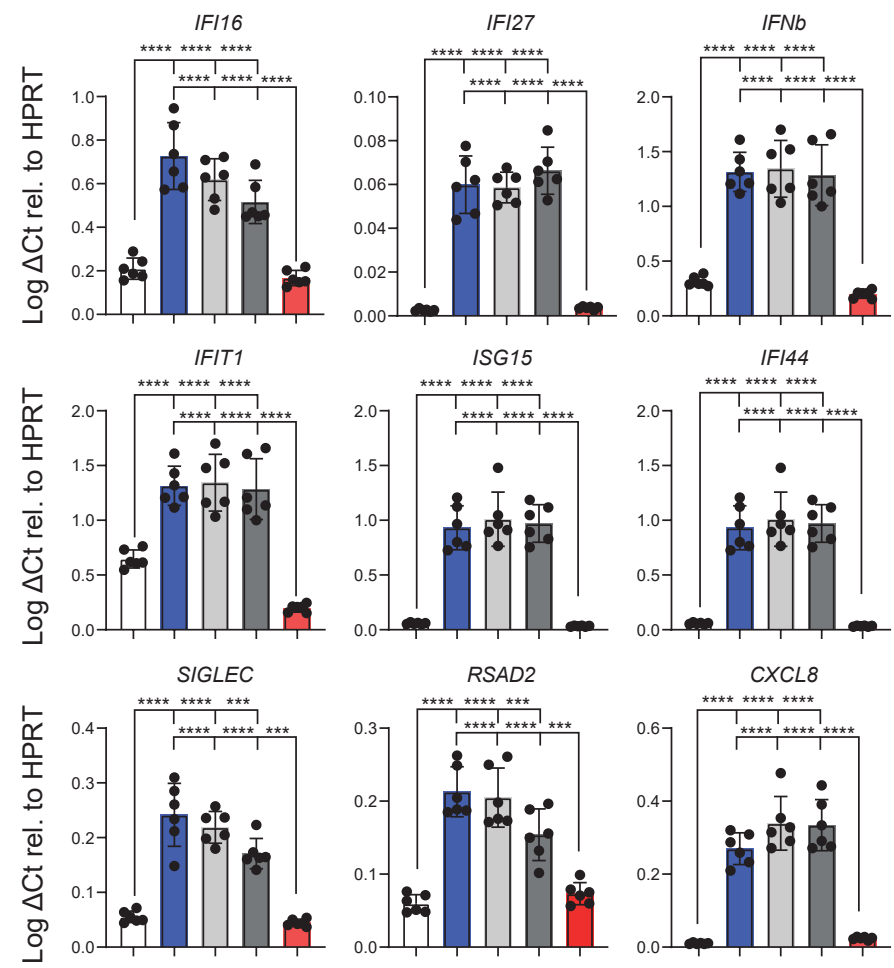

$\mathrm{B}$

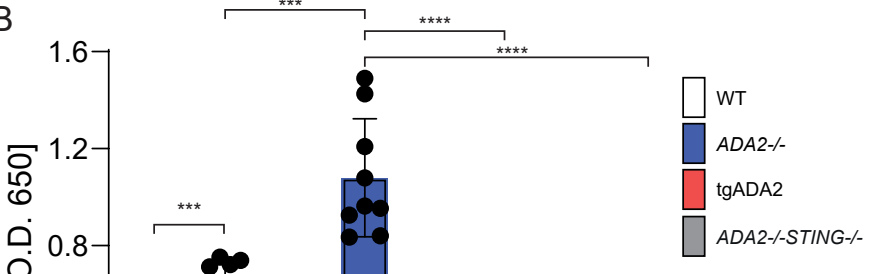

E
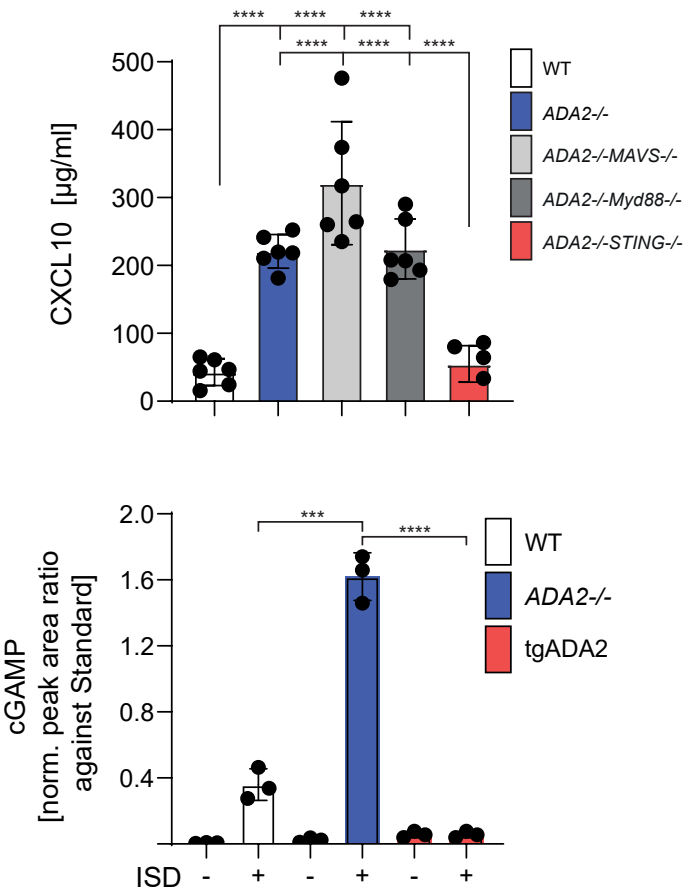
bioRxiv preprint doi: https://doi.org/10.1101/2020.06.21.162990; this version posted June 22, 2020. The copyright holder for this preprint (which was not certified by peer review) is the author/funder, who has granted bioRxiv a license to display the preprint in perpetuity. It is made available under aCC-BY-NC-ND 4.0 International license. 


\title{
Supplementary Materials for
}

\author{
Ole Kristian Greiner-Tollersrud et al
}

\section{ADA2 is a lysosomal DNase regulating the type-I interferon response}

\section{This PDF file includes:}

Materials and Methods

Figs. S1 to S7

Supplementary table 1 to 3 


\section{Materials and Methods}

\section{Monocytes isolation from peripheral blood mononuclear cells}

Peripheral Blood Mononuclear Cells (PBMC) were prepared by centrifugation on a Ficoll gradient (Lymphoprep ${ }^{\mathrm{TM}}$ ). Blood $\mathrm{CD} 14^{+}$monocytes were isolated from DADA2 patients or healthy donors' PBMC by positive selection using magnetic beads (Miltenyi). Monocytes purity was $95 \%-98 \%$ as measured by flow cytometry (see suppl. Fig. 1A).

\section{Sample Preparation for Proteome MS Analysis}

Samples were processed as described by Rieckmann JC et al (1). In brief, cell pellets were washed with PBS and lysed in 8M urea, 10 mM HEPES (pH 8), $10 \mathrm{mM}$ DTT. Cell pellets were sonicated at $4^{\circ} \mathrm{C}$ for $15 \mathrm{~min}$ (level 5, Bioruptor, Diagenode). Alkylation was performed in the dark for $30 \mathrm{~min}$ by adding $55 \mathrm{mM}$ iodoacetamide (IAA). A two-step proteolytic digestion was performed. First, samples were digested at room temperature (RT) with LysC (1:50, w/w) for $3 \mathrm{~h}$. Then, they were diluted 1:5 with $50 \mathrm{mM}$ ammoniumbicarbonate $(\mathrm{pH} 8)$ and digested with trypsin $(1: 50, \mathrm{w} / \mathrm{w})$ at RT overnight. The resulting peptide mixtures were acidified and loaded on $\mathrm{C} 18$ StageTips . Peptides were eluted with $80 \%$ acetonitrile (ACN), dried using a SpeedVac centrifuge (Savant, Concentrator plus, SC $110 \mathrm{~A}$ ), and resuspended in $2 \% \mathrm{ACN}, 0.1 \%$ trifluoroacetic acid (TFA), and $0.5 \%$ acetic acid.

\section{LC-MS/MS for Analysis of Proteomes}

Peptides were separated on an EASY-nLC 1200 HPLC system (Thermo Fisher Scientific) coupled online to a Q Exactive mass HF spectrometer via a nanoelectrospray source (Thermo Fisher Scientific). Peptides were loaded in buffer A $(0.1 \%$ formic acid $)$ on in house packed columns $(75 \mu \mathrm{m}$ inner diameter, $50 \mathrm{~cm}$ length, and $1.9 \mu \mathrm{m} \mathrm{C18}$ particles from Dr. Maisch $\mathrm{GmbH})$. Peptides were eluted with a non-linear 180 min gradient of $5 \%-60 \%$ buffer B (80\% ACN, $0.1 \%$ formic acid) at a flow rate of $250 \mathrm{nl} / \mathrm{min}$ and a column temperature of $50^{\circ} \mathrm{C}$. The Q Exactive was operated in a data dependent mode with a survey scan range of $300-1650 \mathrm{~m} / \mathrm{z}$ and a resolution of $60^{\prime} 000$ at $\mathrm{m} / \mathrm{z} 200$. Up to 10 most abundant isotope patterns with a charge $\geq 2$ were isolated with a $1.8 \mathrm{Th}$ wide isolation window and subjected to higher-energy C-trap dissociation (HCD) fragmentation at a normalized collision energy of 27. Fragmentation spectra were acquired with a resolution of 15,000 at $\mathrm{m} / \mathrm{z} 200$. Dynamic exclusion of sequenced peptides was set to $30 \mathrm{~s}$ to reduce the number of repeated sequences. Thresholds for the ion injection time and ion target values were set to $20 \mathrm{~ms}$ and 3E6 for the survey scans and $55 \mathrm{~ms}$ and 1E5 for the MS/MS scans, respectively. Data were acquired using the Xcalibur software (Thermo Scientific).

\section{Analysis of Proteomics Data}

MaxQuant software (version 1.5.3.54) was used to analyze MS raw files (2). MS/MS spectra were searched against the human Uniprot FASTA database (Version Oct 2017, 71'775 entries) and a common contaminants database (247 entries) by the Andromeda search engine. Cysteine 
carbamidomethylation was set as fixed and N-terminal acetylation and methionine oxidation as variable modification. Enzyme specificity was set to trypsin with a maximum of 2 missed cleavages and a minimum peptide length of 7 amino acids. A false discovery rate (FDR) of $1 \%$ was required for peptides and proteins. Peptide identification was performed with an allowed precursor mass deviation of up to $4.5 \mathrm{ppm}$ and an allowed fragment mass deviation of $20 \mathrm{ppm}$. Nonlinear retention time alignment of all measured samples was performed in MaxQuant. Peptide identifications were matched across different replicates within a time window of $1 \mathrm{~min}$ of the aligned retention times. A minimum ratio count of 1 was required for valid quantification events via MaxQuant's Label Free Quantification algorithm (MaxLFQ). Data were filtered for common contaminants and peptides only identified by side modification were excluded from further analysis.

\section{Bioinformatic analysis of proteomic data}

Proteins with fold change cut-off 1.5 and p-value (Welch's approach) $<=0.05$ were considered to be significantly differentially enriched. R/Bioconductor (version 1.0.1.) $(3,4)$ and DEP package (5) were used for the differential enrichment analysis of the proteomics data. The volcano plot that was constructed to depict the significant deregulated proteins was generated with ggplot2 package (6). Gene ontology and pathway analysis were performed with DAVID knowledgebase(7), only pathways and biological processes with p-value $<=0.05$ were considered significantly enriched. Cytoscape ( 8 ) and Metascape (9) were used for network construction.

\section{FACS sorting from PBMCs or bone marrow bone marrow cellular suspension}

For sorting, either PBMCs or bone marrow cellular suspension were used. The latter were prepared by red blood cell lysis of bone marrow aspirates and subsequent washing with PBS. The cells were stained with the antibodies listed in supplementary table 1 and 2. At the sorting facility, the cells were subjected to a MoFlo Astrios EQ cell sorter. Post-sort controls on the same machine showed a purity of $>98 \%$ for the sorted populations. B cells: lymphocytes FSC/SSC -> CD19 ${ }^{+} \mathrm{CD}^{-}{ }^{-C D} 14^{-}$; Monocytes: monocytes FSC/SSC -> CD19-CD3-CD14 ${ }^{+}$; T cells lymphocytes FSC/SSC -> CD19-CD3 ${ }^{+} \mathrm{CD}^{-} 4^{-}$; Granulocytes: granulocytes FSC/SSC.

Antibodies and relative working dilution used for FACS sorting of peripheral lymphocyte subpopulations

\begin{tabular}{|l|l|l|}
\hline Reagent (catalogue-number) & Company & Dilution \\
\hline CD19 PECy7 (\#557835) & BD Bioscience & $1: 50$ \\
\hline CD27 APC (\#17-0279-42) & eBioscience & $1: 20$ \\
\hline IgM V450 (\#561286) & BD Bioscience & $1: 50$ \\
\hline CD8a PerCPCy5.5 (\#45-0081-80) & eBioscience & $1: 20$ \\
\hline CD4 APCCy7 (\#300517) & BioLegend & $1: 80$ \\
\hline CD3 FITC (\#555916) & BD Bioscience & $1: 100$ \\
\hline CD14 PE (\#555398) & BD Bioscience & $1: 20$ \\
\hline
\end{tabular}




\section{Microscopy}

For histopathological sample analysis, $2 \mu \mathrm{m}$ sections were taken from buffered formalin fixed paraffin embedded biopsies and put on coated slides (SuperfrostPlus, Langenbrinck, Emmendingen, Germany). Staining was done with a primary antibody against CD14 (rabbit monoclonal antibody, clone EPR3653, BioGenex, Fremont, USA), no antigen retrieval was necessary. Secondary antibody was taken from the K5005 kit (Dako) according to the manufacturers guidelines and visualized with an alkaline phosphatase based red chromogen reaction from the K5005 kit (Dako). After denaturation of this first antibodies as described (Poc et al, manuscript in preparation), staining against ADA2 (anti CECR2 rabbbit polyclonal antibody, Sigma-Aldrich, Taufkirchen, Germany) was done after heat mediated epitope retrieval in a steamer for 30 minutes in TRIS buffered saline at pH6.1. The secondary antibody was again taken from the K5005 kit (Dako), visualized by an alkaline phosphatase based blue chromogen reaction (StayBlue/AP, Abcam, Cambridge, UK). Photos were taken with an Olympus BX 51 microscope (Olympus Hamburg, Germany) with the AxioCam MRc microscope camera (Carl Zeiss, Oberkochen, Germany). For immunofluorescence, the protocol by Poc et al was used again. The first staining step was done against LAMP1 (clone eBioH4A3, ThermoFisher, Darmstadt, Germany) after heat mediated epitope retrieval in a steamer for 30 minutes in TRIS buffered saline at pH6.1, visualized in the 488 channel (Alexa488, Thermofisher). The second staining step was done against ADA2 with the antibody as mentioned previously and high pressure cooking epitope retrieval for two minutes in citric buffer $\mathrm{pH} 6$, visualized in the 555 channel (Alexa555, Thermofisher). Nuclei were couterstained with DAPI 1:1000 (ThermoFisher). Images were taken with a fluorescence microscope (Axioplan 2, Zeiss) with the AxioCam MRm microscope camera. For ADA2 detection by Immunofluorescence, slides were prepared prior to cytospin as follows: They were soaked in $\mathrm{NaOH}-\mathrm{Ethanol}$ solution and incubated with gentle rotation for 2 hours at room temperature in order to roughen the surface of the glass for better adhesion. Afterwards, they were washed extensively under running ddH2O for 30 minutes to remove all traces of $\mathrm{NaOH}$. Then, they were coated with $10 \mu \mathrm{g} / \mathrm{mL}$ Poly-DLysin in PBS for 45 minutes. After careful removal of the coating solution, slides were let to dry and stored at room temperature until further usage. Purified granulocytes, monocytes, $\mathrm{T}$ and $\mathrm{B}$ cells from healthy donor EDTA blood or from healthy donor bone marrow aspirates were cytospinned at $700 \mathrm{~g}$ for 5 minutes at room temperature with a Hettich Rotofiy 32A cytospin centrifuge. Cells were fixed with precooled $1: 1$ acetone/methanol fixative 20 minutes at $-20^{\circ} \mathrm{C}$. Afterwards the fixative was aspirated, and the sample washed three times in PBS for 5 minutes. Then, the cells were blocked with blocking solution (5\% human serum in PBS) for 1.5 hours at room temperature. Hereafter, cells were immunostained with a rabbit anti-human-CECR1 (HPA007888 Sigma; 1:100) in blocking solution over night at $4^{\circ} \mathrm{C}$; or with the isotype control at the same concentration (Purified Rabbit IgG, P120-101 Bethyl; 1:2500), respectively. The next morning, they were washed with PBS twice for 5 minutes and stained again simultaneously with an anti-rabbit IgG conjugated with Anti-rabbit IgG Alexa Fluor ${ }^{\circledR} 555$ (1:500) and Hoechst $(1: 1000=10 \mu \mathrm{g} / \mathrm{mL})$ in blocking solution for 30 minutes at room temperature in the dark. After two washes with PBS, Prolong ${ }^{\circledR}$ Gold Anti-fade Reagent and coverslip slides were mounted on the slides. Then, images were aquired with a Zeiss LSM 710 and later analyzed with Zen imaging-software (Zeiss). 


\section{Modeling of dsDNA binding to ADA2 and comparison between ADA2 and ADA1 structure}

The crystal structure of ADA2 (3LGD) and double stranded DNA (1D66) were used for proteinDNA docking using HDOCK server (DOI:10.1093/nar/gkx407). The top scored complex was subjected to steered molecular dynamic simulation using a TIP3P water model in a solvated box under periodic boundary conditions. Minimization was performed using 100 steepest descent steps at $0.02 \AA$ followed by 10 steps of conjugate gradient at $0.02 \AA$. Equilibration was performed for 100000 steps (time step $1 \mathrm{fs}$ ) using heater temperature control method. Production was performed for 100000 steps (time step 1fs). Molecular dynamic simulation was performed with UCSF Chimera (10). Molecular images were produced using PyMOL Molecular Graphics System, Version 2.0 Schrödinger, LLC.

\section{ADA2 WT and ADA2 mutants production and purification}

Protein production was performed in $100 \mathrm{ml}$ (small scale screening), and a selection of the mutants in 11 (large scale). ADA2 plasmid DNA (uniprot Q9NZK5: aa29-511) with a CD33 leader on its N-terminus and a APP- and His6 tag on its $\mathrm{C}$ terminus was transfected with the PEI method in HKB11 mammalian cells. Fresh grown cells $\left(1.25 \times 10^{8}\right.$ cells $)$ have been centrifuged, resuspended in $9 \mathrm{ml}$ fresh M11V3 media (Bioconcept, \#V3-k) and transferred into $250 \mathrm{ml}$ shake flask. $75 \mathrm{ug}$ DNA and $225 \mathrm{ug}$ PEI have been transferred in $1.75 \mathrm{ml}$ media each and incubated for 5 min in separate. After transfer of PEI to DNA and gentle mixing, both have been incubated for another 15 minutes at RT. Then, DNA- and PEI-Mix has been added to cells and incubated for four hours in shaking incubator (standard cultivation conditions with shaking at $115 \mathrm{rpm}$ at $37^{\circ} \mathrm{C}$ with $5 \% \mathrm{CO}_{2}$ and $80 \%$ humidity). Subsequently, transfected cells have been fed with $87.5 \mathrm{ml}$ M11V3-media, and then incubated for 7 days in shaking incubator. For a 11 large scale expression with a selection of some mutants, this protocol has been scaled up. Protein was purified from the cell supernatant by ion metal affinity chromatography (IMAC) using the Histag and rebuffered into PBS, pH7.4. Subsequently, proteins from 11 large scale production have been polished on preparative SEC (Superdex75 column, GE Healthcare, 28-9893-33). Protein integrity and purity was analyzed by SDS-PAGE and mass spectroscopy (HPLC-ESIMS). The dimerization of the total protein was confirmed by size exclusion chromatography (SEC) and inline multi-angle light scattering (MALS). Human Macrophage colony-stimulating Factor1Receptor (aa20-512), which comprises nearly the complete extracellular domain of hCSF1Receptor (aa20-517; UniprotKB-P07333, full length aa1-972) and a His-tag, was expressed and purified as ADA2 and used as a control

\section{$D N A S e$ and ADA activity of wild type and mutant human recombinant ADA2}

ADA2 DNAse of recombinant human ADA2 has been measured by a commercial Fret assay (Thermofisher - AM1970 DNaseAlert). In brief, 6ul ADA2 solution at a final concentration of $10 \mathrm{ug} / \mathrm{ml}$ was incubated with 3ul DNA-substrate and 40ul of MIB super buffer 2 (Malonic acid: Imidazole: Boric acid in the molar ratios 2:3:3) or CHC super buffer 1 (Citric acid:HEPES:CHES in the molar ratios 2:3:4) (Jena Bioscience CS-332- JBScreen Thermofluor Fundament) at the indicated $\mathrm{pH}$ and $\mathrm{NaCl}$ concentration. Break down of DNA was measured every 2 mins for 30 minutes with a fluorescent reader (Spectramax, excitation $535 \mathrm{~nm}$ and emission 575nm). ADA2 DNAse of small scale purified recombinant human ADA2 mutants has been measured by fret assay at $25 \mu \mathrm{g} / \mathrm{ml}$. the G358R mutant was purified at large scale and its DNAse activity measured at $\mathrm{pH} 4.8$ at different protein concentration and compared to WT 
human ADA2, human ADA1 and a control protein expressed by the same cell type of hADA2 and purified with the same protocol and machinery. Adenosine Deaminase (ADA) activity has been measured by a commercial assay (Diazyme-DZ117A-K), which is specific for ADA and has no detectable reaction with other nucleosides. $5 \mathrm{ul}$ of ADA2 or control proteins were added to 180ul of buffer R1 and incubated $3 \mathrm{~min}$ at $37^{\circ} \mathrm{C}$, then $90 \mathrm{ul}$ of buffer R2 was added and the plate was incubated at $37^{\circ} \mathrm{C}$ for $20 \mathrm{~min}$. The enzymatic activity was monitored by the measurement of the OD at 550nm with a temperature controlled fluoresecent reader (Synergy H1 from Biotek).

\section{Mass spec analysis of recombinant human ADA2}

$1 \mu \mathrm{g}$ of protein was resuspended in 8M urea, $10 \mathrm{mM}$ HEPES (pH 8), 10 mM DTT. Alkylation was performed in the dark for $30 \mathrm{~min}$ by adding $55 \mathrm{mM}$ iodoacetamide (IAA). A two-step proteolytic digestion was performed. First, samples were digested at room temperature (RT) with LysC (1:50, w/w) for $3 \mathrm{~h}$. Then, they were diluted 1:5 with $50 \mathrm{mM}$ ammoniumbicarbonate $(\mathrm{pH} 8)$ and digested with trypsin $(1: 50, \mathrm{w} / \mathrm{w})$ at $\mathrm{RT}$ overnight. The resulting peptide mixtures were acidified and loaded on C18 StageTips. Peptides were eluted with $80 \%$ acetonitrile (ACN), dried using a SpeedVac centrifuge (Savant, Concentrator plus, SC 110 A), and resuspended in 2\% ACN, $0.1 \%$ trifluoroacetic acid (TFA), and $0.5 \%$ acetic acid. Peptides were separated on an EASY-nLC 1200 HPLC system (Thermo Fisher Scientific) coupled online to a Q Exactive mass HF spectrometer via a nanoelectrospray source (Thermo Fisher Scientific). Peptides were loaded in buffer $\mathrm{A}(0.1 \%$ formic acid $)$ on in house packed columns $(75 \mu \mathrm{m}$ inner diameter, $50 \mathrm{~cm}$ length, and $1.9 \mu \mathrm{m} \mathrm{C18}$ particles from Dr. Maisch $\mathrm{GmbH})$. Peptides were eluted with a nonlinear 120 min gradient of $5 \%-60 \%$ buffer $\mathrm{B}(80 \% \mathrm{ACN}, 0.1 \%$ formic acid) at a flow rate of 250 $\mathrm{nl} / \mathrm{min}$ and a column temperature of $50^{\circ} \mathrm{C}$. Raw files were analyzed by MaxQuant software (version 1.5.3.54). The mass spectrometry proteomics data have been deposited to the ProteomeXchange Consortium via the PRIDE (11) partner repository with the dataset identifier PXD019382.

\section{Porcine brain ADA2 purification}

A schematic overview of the ADA2 purification steps from $5 \mathrm{~kg}$ porcine brains obtained freshly from the local slaughterhouse is shown in Suppl. Fig. S4. The brain was cut into small pieces and homogenized in $0.075 \mathrm{M}$ acetic acid/0.15 M NaCl (1:2 mass/vol.) using a Waring blendor. The homogenate was centrifuged at $10000 \mathrm{~g}$ for $10 \mathrm{~min}$. The $\mathrm{pH}$ of the supernatant was adjusted by adding $1 \mathrm{M}$ TRIS base until the $\mathrm{pH}$ reached 7.6. It was then heat treated at $60^{\circ} \mathrm{C}$ for $20 \mathrm{~min}$ and centrifuged as before. The supernatant was added $20 \mathrm{ml}$ Concanavalin A Sepharose and stirred overnight at $4^{\circ} \mathrm{C}$. The slurry was run through a column and washed with PBS. The glycoproteins including ADA2 was eluted using 0.2 $\mathrm{M} \alpha$-methylmannoside in PBS. The protein solution was subsequently loaded onto a $20 \mathrm{ml}$ hydroxyapatite column equilibrated with PBS and the proteins eluted with a stepwise phosphate concentration. The main bulk of ADA2 eluted at $0.05 \mathrm{M}$ phosphate. After dialysis against $0.02 \mathrm{M}$ Tris, $\mathrm{pH} 7.6$ this fraction was applied to a DEAE anion exchange column equilibrated with the same buffer. ADA2 appeared in the run through fraction. It was concentrated and applied to a Sephadex S-200 gel filtration column. The ADA2 isomer with high plasmid DNase activity coeluted with arylsulphatase B with a native mass of about 60 $\mathrm{kDa}$. This fraction was dialyzed against $0.02 \mathrm{M}$ Tris, $\mathrm{pH} 7.6$ and subjected to $\mathrm{CM}$ cation exchange chromatography using a continuous $\mathrm{NaCl}$ salt gradient. ADA2 eluted at about $0.08 \mathrm{M}$ $\mathrm{NaCl}$ and this fraction was dialyzed against $0.02 \mathrm{M}$ Tris, $\mathrm{pH}$ 7.6. After dialysis against $0.02 \mathrm{M}$ 
Tris, $\mathrm{pH} 7.6$ the samples were run in heparin Sepharose chromatography and the ADA2 isomer with high plasmid DNase activity bound strongly to heparin and was eluted at about $0.1 \mathrm{M} \mathrm{NaCl}$. We assessed the purity of the final preparation of ADA2 by SDS/PAGE and MS/MS analyses (Suppl. Fig. 4). The mass spectrometry proteomics data have been deposited to the ProteomeXchange Consortium via the PRIDE (11) partner repository with the dataset identifier PXD019373

\section{MS/MS-analysis or porcine brain proteins}

Gel pieces were subjected to in gel reduction, alkylation, and tryptic digestion using $6 \mathrm{ng} / \mu \mathrm{l}$ trypsin. OMIX C18 tips (Varian, Inc., Palo Alto, CA, USA) was used for sample cleanup and concentration. Peptide mixtures containing $0.1 \%$ formic acid were loaded onto a Thermo Fisher Scientific EASY-nLC1000 system and EASY-Spray column $(\mathrm{C} 18,2 \mu \mathrm{m}, 100 \AA, 50 \mu \mathrm{m}, 15 \mathrm{~cm})$. Peptides were fractionated using a 2-100\% acetonitrile gradient in $0.1 \%$ formic acid over $50 \mathrm{~min}$ at a flow rate of $250 \mathrm{nl} / \mathrm{min}$. The separated peptides were analysed using a Thermo Scientific QExactive mass spectrometer. Data was collected in data dependent mode using a Top10 method. The Proteome Discoverer 1.4 software was used to generate mgf peak list files. The mgf files was searched against a mammalian database using an in-house Mascot server (Matrix Sciences, UK). Peptide mass tolerances used in the search were $10 \mathrm{ppm}$, and fragment mass tolerance was $0.02 \mathrm{Da}$.

\section{Site specific analysis of $N$-glycan structures linked to porcine brain proteins}

The N-glycan analysis was carried out essentially as previously described (12), but without spectral aligning, due to the purity of the proteins. 1) The peptide sequences of the glycopeptides were determined by calculating the theoretical masses of the tryptic peptides containing NXS/T glycosylation sequons of the target protein. The calculated masses of each of these peptides attached to more than 250 different $\mathrm{N}$-glycan structures were determined and compared to all of the peptide masses obtained from the MS/MS spectra. Those masses that matched were analysed further. 2) The MS/MS-spectra containing glycopeptides were identified by the typical oxonium ions of simple sugars, m/z 163.1 (Hex), m/z 204.1 (HexNAc) and m/z 366.1 (HexHexNAc). Spectra containing mannose-6-phosphorylated glycans were identified by the additional ions, $\mathrm{m} / \mathrm{z} 243.1$ (PHex), and its fragmentation ion, $\mathrm{m} / \mathrm{z}$ 225.1. 3) Next, each individual glycopeptide spectrum was scanned for the presence of fragmentation ions with a similar mass as the deglycosylated peptide, and ions with an additional mass of 203.1, corresponding to linkage with a single HexNAc. 4) The identity of the peptide part was further confirmed by the identification of fragmentation ions corresponding to the calculated y-, b-values. 5) The glycan structure linked to the peptide was deduced from a comparison between its mass as determined from the MS/MS-spectrum and theoretical masses of N-glycan structures. The glycan structures were divided into the following groups, as mentioned in Fig. 2D: SN3, sialylated complex structure with three GlcNAc's linked to the core; SN2, sialylated complex structure with two GlcNAcs linked to the core; SN1, sialylated complex structure with one GlcNAc linked to the core; NN3, neutral complex structure with three GlcNAcs linked to the core; NN2, neutral complex structure with two GlcNAcs linked to the core; NN1, neutral complex structure with one GlcNAc linked to the core; LMF, core-fucosylated structure with 1-3 mannoses linked to the core chitobiose unit; P2M, bisphosphorylated oligomannosidic structure; P1M, monophosphorylated oligomannosidic structure; HM, oligomannose with 6-9 mannose; MM, oligomannose with 4-5 mannose; LM, oligomannose with 1-3 mannose. 
Evaluation of porcine brain mediated DNAse activity.

The DNA substrate was pcDNA 3.1 with a MEK1 insert (a gift from Ugo Moens, University of Tromso). $10 \mu \mathrm{l}$ reaction sample containing $25 \mathrm{mM}$ acetic acid buffer of different $\mathrm{pH}, 0.2 \mu \mathrm{g}$ plasmid DNA, $0.5 \mu \mathrm{g}$ BSA and the ADA2 sample, was incubated at room temperature for 10 min, and the reaction stopped by adding $2 \mu 1$ of $1 \mathrm{M}$ Tris base. The DNA fragments were separated by $1.5 \%$ agarose gel electrophoresis. RedSafe ${ }^{\mathrm{TM}}$ nucleic acid staining solution was used to visualize DNA. For standard assays the $\mathrm{pH}$ of the buffer was typically 4.8 , corresponding to the $\mathrm{pH}$-optimum for both ADA2 and DNase2.

\section{THP1 cells culture, propagation, differentiation and stimulation}

THP-1 cells were grown in RPMI 1640 10\% FBS, 2 mM L-glutamine. The cells were maintained at a density between $2.5 \times 10^{\wedge} 5$ cells $/ \mathrm{ml}$ to $5 \times 10^{\wedge} 5$ cells $/ \mathrm{ml}$, changing the medium every two-three days. Before stimulation the cells were stimulated $6 \mathrm{hrs}$ with $50 \mathrm{nM}$ phorbol 12 myristate 12-acetate [PMA, Sigma P8139], washed twice and stimulated with the following stimuli. THP1 cell lines were pre-activated with PMA [50nM] washed twice with RPMI 10\% FCS and subsequently stimulated over night with the following stimuli: Poly-IC (Invivogen https://www.invivogen.com/ cat. num. 31852-29-6, working concentration $1 \mu \mathrm{g} / \mathrm{ml}$, with lipofectamine LTX Invitrogen ratio dsDNA/Lipofectamine, $1 \mu \mathrm{g} / \mu \mathrm{l}$ ), LPS (Invivogen https://www.invivogen.com/ cat. num. tlrl-eklps, working concentration $10 \mathrm{ng} / \mathrm{ml}$ ), Imiquimod (Invivogen https://www.invivogen.com/ cat. num. tlrl-imqs, working concentration $1 \mu \mathrm{g} / \mathrm{ml}$ ), ISD70 (VACV 70mer-derived DNA 'CCATCAGAAAGAGGTTTAATATTTTTGTGAGACCATCGAAGAGAGAAAGA GATAAAACTTTTTTACGACT-3', synthetized by SigmaAldrich, working concentration $1 \mu \mathrm{g} / \mathrm{ml}$, complexed with lipofectamine LTX Invitrogen; ratio dsDNA/Lipofectamine, $1 \mu \mathrm{g} / 1 \mu \mathrm{l}$ ).

\section{CRISPR-Cas9 knockout of ADA2 and STING in THP1 cells}

CRISPR-Cas9 technology was used to generate ADA2 or ADA2/STING knockout THP1 cells. The AATCAAGTTCCCCACGGTGG guide RNA targeting exon 5 of ADA2 and the CTAGCCCCCAAAGGGTCACC targeting exon 4 of STING were get from http://crispr.mit.edu have been cloned into the minimal plasmid pMAX-Crispr with Cas9-2A-eGFP (provided by dr. Bartok E) using Gibson assembly. Briefly the vector was linearized with SwaI, the gRNA was annealed at equimolar ratio with the universal antisense Oligo:

GCCTTATTTTAACTTGCTATTTCTAGCTCTAAAAC (annealing cycling: $95^{\circ} \mathrm{C} / 5 \mathrm{~min}$, gradient $-1^{\circ} \mathrm{C} / 30 \mathrm{sec}, 80$ cycles), the annealed oligos were filled-in with Klenow fragment and finally assembled with the digested vector. Stbl3 competent E. coli were transformed with $2 \mu 1$ of Assembly. Single colonies were grown in LB (kanamycin), plasmid DNA extracted and Saanger sequenced to confirm the insertion. THP1 cells were electroporated $\left(10 \mu \mathrm{g} / 1,25 \times 10^{\wedge} 6\right.$ cells $)$ using NEON system. The setting of electroporation was the following: 1250V, 1 pulse, $20 \mathrm{~ms}$. The day after electroporation, GFP positive cells have been FACS sorted into 384 well at a density of 0.5 cells/well in RPMI 10\% FCS. The growing clones have been screened for gene $\mathrm{KO}$ by western blot and/or Sanger sequencing after PCR amplification of the target exon.

Lentivirus transduction of THP1-/- cells with ADA2. 
The ADA2 protein (uniprot Q9NZK5: aa29-511), was clone into pLenti-GFP-puro plasmid. HEK293 cells were transfected with pLenti-ADA2-IRES-GFP-Puro, psPAX2 and pMD2G to produce lentiviral particles. After $48 \mathrm{hrs}$ from transfection the supernatant was transferred to THP1 cells and incubated $16 \mathrm{hr}$ a humidified incubator in an atmosphere of 5-7\% CO2. After this time the media containing lentiviral particles was removed and substituted with fresh medium. The efficiency of transduction was monitored measuring GFP expression by flow cytometry (BD Fortessa). Transduced cells were used for experiments starting from three weeks after transduction.

\section{SDS-PAGE and Western Blotting}

Stimulated or unstimulated cells were transferred into eppendorf tubes and centrifuged at $200 \mathrm{~g}$ for $5 \mathrm{~min}$ at room temperature. The supernatant was discarded, and the pellet was resuspended in $5 \mathrm{ml}$ cold PBS. After two washing steps of 5 minutes at $4{ }^{\circ} \mathrm{C}$ (first: $200 \mathrm{~g}$; second: top speed, $18,000 \mathrm{~g})$, the pellet was resuspended in lysis buffer $(200 \mu \mathrm{l}$ per $10 \times 106$ cells) and 1\% PMSF. After 25 minutes incubation on ice, they were sonicated for 20 minutes and finally centrifuged at top speed for 10 minutes at $4^{\circ} \mathrm{C}$. The protein concentration was determined with the Pierce ${ }^{\mathrm{TM}}$ BCA Protein Assay Kit according to the manufacturer's protocol. In order to reach a final volume of $30 \mu \mathrm{L}, 5 \mu \mathrm{L}$ of $6 \mathrm{x}$ Laemmli buffer (see below) and the missing amount of ddH20 was added to the appropriate volume of cell lysate, containing $20-35 \mu \mathrm{g}$ of total protein. The samples were incubated at $70^{\circ} \mathrm{C}$ for $10 \mathrm{~min}$ and afterwards used directly or stored at $-80^{\circ} \mathrm{C}$. After the heating step, lysates and protein markers were loaded on a $10 \%$ polyacrylamide gel (see below), using a Bio-Rad Mini-PROTEAN Electrophoresis System. The samples were subjected to electrophoresis at $80 \mathrm{~V}$ for 30 minutes and subsequently $110 \mathrm{~V}$ for another 90 minutes in 1x SDS running buffer. After electrophoresis, the proteins were transferred under wet conditions to a PVDF membrane using the same Bio-Rad Mini-PROTEAN System in $1 \mathrm{x}$ transfer buffer (see below) at $45 \mathrm{~V}$ for $90 \mathrm{~min}$. Afterwards, the membrane was blocked in blocking buffer (5\% powdered milk in Tris-buffered saline (TBS) $+1 \%$ Tween $20=$ TBST) for 1 hour at room temperature. Then, the membrane was incubated with the primary antibodies (anti-CECR1 HPA007888, sigma dilution 1:100, anti-STING, 675902 biolegend dilution 1:500, in blocking buffer plus $0.02 \%$ sodium azide in TBST) over night at $4^{\circ} \mathrm{C}$, followed by 3 washes with TBST. The secondary antibody was also diluted in blocking buffer and the applied for 1 hour at room temperature. After 3 more washes with TBST and another wash with TBS, protein detection was performed using LumiGLO ${ }^{\circledR}$ chemiluminescent substrate according to the manufacturer's instructions. After an HRP-inactivation step with 10\% sodium azide in blocking buffer (1 hour at room temperature), anti- $\beta$-Actin was stained subsequently as a loading control, following the same protocol.

\section{Detection of ADA2, pIRF3, and secreted IFN in THP-1 cells after stimulation}

THP-1 cells were stimulated with ISD, cGAMP, poly-IC, Imiquimod, ODN-2006 and lipopolysaccharide (LPS) as a control. ADA2, pIRF3, and $\beta$ actin was detected in cell lysates by automated western blot system (WES, ProteinSimple) using rabbit anti ADA2/CECR1 (Novusbio; \# NBP1-89238), rabbit anti pIRF3 (phospho S386; Abcam \# ab76493) and anti $\beta$ actin (Sigma; \# A5441). 
One million cells have been lysed with $400 \mathrm{uL}$ cold methanol $\left(-80^{\circ} \mathrm{C}\right)$ (Sigma-Aldrich, Germany) containing [15N5]-2,3-cGAMP (Novartis, Switzerland) as internal standard (IS). The collected extract was dried down and resuspended in 100uL 80\% acetonitrile (Sigma-Aldrich, Germany). $10 \mathrm{uL}$ of this solution was injected for LC-MS/MS analysis. The QTRAP 6500 mass spectrometer (SCIEX, Framingham, MA) was coupled to liquid chromatography (Thermo Fisher Scientific, Waltham, MA). 2,3-cGAMP and IS were detected in the positive ion mode with the mass transition 675.1/524.0 for cGAMP and 680.1/528.9, respectively. All results are given as normalized peak area ratio of cGAMP against IS.

HEK-Blue IFN- $\alpha / \beta$ report cells culture and propagation and IFN- $\alpha / \beta$ secretion measurement.

HEK-Blue IFN- $\alpha / \beta$ report system was used to detect Type-I IFN, following the protocol described by the manufacturer. Briefly, cells were maintained in DMEM containing Blasticidin $(30 \mu \mathrm{g} / \mathrm{ml})$ and Zeocin $(100 \mu \mathrm{g} / \mathrm{ml})$. For detection of Type-I interferon, $180 \mu 1$ of cell suspension containing 50000 cells were transferred into each well of a 96 flat well plate. The cells were incubated in the incubator for $2 \mathrm{hr}$. Subsequently $20 \mu \mathrm{l}$ of supernatant were transferred into each well and incubated $24 \mathrm{hr}$. IFN-alfa was used as positive control. After incubation $20 \mu \mathrm{l}$ of cell culture medium were mixed with $180 \mu 1$ of QUANTI-Blue and type-I IFN detected by spectrophotometer at $660 \mathrm{~nm}$. 
Fig. S1.

Proteomes of ADA2 deficient monocytes cells

(A) FACS analysis of monocytes purification after magnetic activated cell sorting. (B) $A D A 2$ mutations in DADA2 patients used for monocytes isolation and monocyte proteomes analysis.

(C) LFQ intensity of selected proteins known to be mutated in patients with Type I Interferonopathies (13).

Fig. S2.

Correlation between ADA2 and ISGs protein levels in proteomes of DADA2 and healthy controls.

Left panels: LFQ intensity of different interferon induced genes was compared between healthy controls, DADA2 patients with undetectable ADA2 (ADA2 ${ }^{\text {null }}$ ) and DADA2 patients with residual ADA2 protein (ADA2 ${ }^{\mathrm{dim}}$ ) (line over the bars represent the statistical comparison, unpaired t.test was used for comparison, , $*=p<=0.01, * *=p<=0.001, * * *=p<=0.0001$. Right panels: correlation between ADA2 and ISG protein levels. The lines show the result of the nonlinear regression and the texts the obtained $\mathrm{R}$ squared values.

Fig.S3.

Generation of ADA2 ${ }^{-/-}$monocyte THP1 cell line.

(A) ADA2 Western Blot analysis of ADA2, pIRF3, and beta-actin expression in WT $A D A 2^{-/}$and $A D A 2^{-/-}$lentivirus transduced with recombinant human ADA2 THP1 cells. (B) Sanger sequencing of $A D A 2$ gDNA region (exon 5) targeted by the guide

CTAGCCCCCAAAGGGTCACC in the selected exon 5 of ADA2 of the $A D A 2^{-/-}$THP1 selected cell clone.

\section{Fig. S4.}

Histopathology of DADA2 secondary lymphoid organs and expression of ADA2 in tingible body macrophages. (A-E) Lymph node; (A) Few follicles (pointed by arrowhead) withou germinal centers. (B) CD3 staining displays normally distributed T-cells (arrowhead points to Bcell follicle with lower density of CD3+ T-cells). (C) Lack of IgG+ plasma cells. Serum is IgG positive due to replacement therapy. The expanded stroma of the lymph node is highlighted by asterisk. (D) Severely ectatic subcapsular sinus (dotted line) with multiple macrophages, most of them foam cells histiocytosis. (E) CD68 displays the multiple macrophages of the sinus F) Spleen: Intact periarteriolar lymphocytic sheath (pointed by arrowhead) next to an infarction (kollagenous scar tissue marked by asterisk, fibrin marked by double asterisk). (G-H) Immunohistochemistry of human tonsil showing CD14 (red) and ADA2 (blue); dotted line show germinal centers with cytoplasmic ADA2 positivity (asterisk, exemplary) in tingible body macrophages; CD14 (red) highlights the follicular dendritic cell meshwork (10x original magnification). In higher magnifications (bottom panels), $\mathrm{CD}_{1} 4^{+}$dendritic cells in the crypt epithelium (left panel) and surface epithelium (right panel) show few small ADA2 positive intracytoplasmic granules (highlighted by arrowheads, exemplary; 20x original magnification). 
Fig. S5.

Porcine brain ADA2

(A) Alignment between Sus Scrofa and Homo Sapiens protein ADA2 sequences showing percentage of identity. (B) Comparison between Sus Scrofa (yellow) and Homo Sapiens (Red) ADA2 structure. Highlighted in gray is the PRB domain. Homology between human and porcine ADA2. RNA expression of ADA2 in different cell subtypes isolated from human brain, values are expressed in fragments per kilobase of exon (FPKM) (14).

\section{Fig. S6. \\ Purification of endogenous ADA2}

The figure shows the experimental workflow used for the purification of ADA2 from porcine brain, as described in the methods section. (A) Glycoproteins of a heat-treated porcine brain homogenate were enriched by concanavalin A affinity chromatography (step 1). ADA2 was eluted at $0.05 \mathrm{M}$ phosphate on hydroxyapatite chromatography (step 2), which was instrumental to remove any traces of DNase2. As shown in (B), DNase2 dependent DNase activity eluted on hydroxyapatite chromatography at $0.15 \mathrm{M}$ phospate, while ADA2-mediated DNase activity at $0.05 \mathrm{M}$. The picture in (B) shows degradation of plasmid DNA after incubation with various fractions from hydroxylapatite chromatography; on left side left side porcine brain proteins after step 1, and on right side a commercial preparation of partially purified DNAse 2 from porcine spleen. The DNase containing fraction from step 2 was dialyzed against $0.02 \mathrm{M}$ Tris, $\mathrm{pH} 7.6$ and loaded onto a DEAE column (step 3). The DNase activity appeared in the run through, was concentrated and loaded onto a gel filtration column (step 4). The DNase activity coeluted with arylsuphatase $\mathrm{B}(\mathrm{ArsB})$ with a native mass of $60 \mathrm{kDa}$. After dialysis against $0.02 \mathrm{M}$ Tris, $\mathrm{pH}$ 7.6, the eluate was loaded onto a CM Sepharose cation exchange column (step 5). The DNase activity eluted at about $0.08 \mathrm{M} \mathrm{NaCl}$, and SDS/PAGE revealed only two major proteins, ADA2 and ArsB. After dialysis against $0.02 \mathrm{M}$ Tris, $\mathrm{pH}$ 7.6, the partially purified DNase was subjected to heparin Sepharose chromatography (step 6). The DNase activity eluted at high salt concentration. (D) MS/MS analyses of tryptic peptides from each band detected on an overloaded SDS/PAGE after one round of heparin Sepharose chromatography (E) revealed that each of the detectable bands contained predominantly ADA2-sequences, except a band of 42 $\mathrm{kDa}$, where the highest score was caused by heavy chain of ArsB (D). Repeated rounds on heparin Sepharose removed all traces of ArsB, which bound with less affinity than the highly DNase active ADA2-isoform (F).

\section{Fig. $\mathbf{S 7}$}

(A) Mass spectrometry analysis made in triplicates of the WT recombinant human ADA2, G47A ADA2 mutant and His/tag purification control and (lower panels) DNAse and ADA activity of the analyzed proteins. (B) The crystal structure of human ADA2 (PDB ID code 3LGD) was used for modelling mutations. Modelling and structural analysis were performed using the program Coot (15). Structural illustrations were prepared with PyMOL (www.pymol.org). Comparison between the ADA1 (PDB entries: 3IAR) (34), and ADA2 (3LGD) structure showing the absence of a 40 amino acids insertion (aa 111-147), corresponding to the PRB domain in ADA1 in comparison to ADA2. (C) Evaluation of DNase and ADA activities of 8 recombinant ADA2 mutants, ADA1 and Control His tag protein purified with IMAC and SEC (see Suppl. Table . 
bioRxiv preprint doi: https://doi.org/10.1101/2020.06.21.162990; this version posted June 22,2020 . The copyright holder for this preprint (which was not certified by peer review) is the author/funder, who has granted bioRxiv a license to display the preprint in perpetuity. It is made available under aCC-BY-NC-ND 4.0 International license.

\section{Supplementary Table 1}

\begin{tabular}{|c|c|c|c|c|}
\hline Gene names & Fold & pvalue Welchs appr & Log2 Fold & cat \\
\hline GBP5 & 50.39584264 & 0.001177094 & 5.65523282 & up \\
\hline IGHM & 23.33686829 & 0.018032223 & 4.544539065 & up \\
\hline LBP & 20.39702692 & 0.019803732 & 4.350286974 & up \\
\hline GCH1 & 18.38268432 & 0.0005526 & 4.200275545 & up \\
\hline EEF1A1 & 17.42917645 & 0.025539687 & 4.123432497 & up \\
\hline RABGAP1L & 17.0581944 & 0.012366131 & 4.092393041 & up \\
\hline LGALS3BP & 14.2110656 & 0.018617344 & 3.828942833 & up \\
\hline GBP4 & 10.50042178 & 0.000224447 & 3.392375374 & up \\
\hline SP110 & 9.126911856 & 0.000945551 & 3.190126798 & up \\
\hline IFIT1 & 8.235154358 & 0.001844513 & 3.041795692 & up \\
\hline GBP1 & 7.594975943 & 0.000523235 & 2.925045395 & up \\
\hline GK2 & 7.240289198 & 0.020971422 & 2.856047324 & up \\
\hline VNN1 & 6.537666184 & 0.019261208 & 2.708775714 & up \\
\hline TMEM87A & 6.477921801 & 0.015022362 & 2.695531053 & up \\
\hline IFIT3 & 6.161490753 & 0.000702687 & 2.623279449 & up \\
\hline FBXO6 & 5.690830777 & 0.005451176 & 2.50863928 & up \\
\hline APOL3 & 5.524185194 & 0.001017274 & 2.465761686 & up \\
\hline OAS3 & 4.928858294 & 0.000463213 & 2.301253504 & up \\
\hline ANKRD22 & 4.758796413 & 0.002132652 & 2.250596736 & up \\
\hline \multirow[t]{2}{*}{ XAF1 } & 4.393104568 & 0.039661215 & 2.13524084 & up \\
\hline & 4.373577069 & 0.034063579 & 2.128813716 & up \\
\hline HBB & 4.321613826 & 0.036914328 & 2.111570161 & up \\
\hline VAMP5 & 4.038168198 & 0.000233074 & 2.013701003 & up \\
\hline ACTG1 & 3.978733671 & 0.049499754 & 1.992309331 & up \\
\hline ССТ6В & 3.935992914 & 0.003399854 & 1.976727623 & up \\
\hline TBC1D8 & 3.898957636 & 0.025414911 & 1.963088479 & up \\
\hline FCGR3B & 3.706146522 & 0.020257313 & 1.889919919 & up \\
\hline APOL2 & 3.705562118 & 0.000190385 & 1.88969241 & up \\
\hline STAT1 & 3.527030138 & 0.000204879 & 1.818453904 & up \\
\hline GBP2 & 3.447025554 & $9.51302 \mathrm{E}-05$ & 1.785351994 & up \\
\hline RELB & 3.439057865 & 0.004887603 & 1.782013391 & up \\
\hline NEMF & 3.252839626 & 0.041383441 & 1.701699695 & up \\
\hline PARP9 & 3.239813297 & $8.17945 \mathrm{E}-05$ & 1.695910676 & up \\
\hline KAT8 & 3.225405542 & 0.008517995 & 1.689480567 & up \\
\hline SIGLEC10 & 3.208822805 & 0.042033219 & 1.682044124 & up \\
\hline IGHG3 & 3.191639444 & 0.026074773 & 1.674297681 & up \\
\hline MX1 & 3.176458951 & 0.000320443 & 1.667419376 & up \\
\hline LIG4 & 3.112497217 & 0.013038706 & 1.638072547 & up \\
\hline ISG20 & 3.102474927 & 0.001185445 & 1.633419551 & up \\
\hline CASP7 & 3.034866531 & 0.014642362 & 1.60163307 & up \\
\hline ARHGEF11 & 2.977157005 & 0.009281575 & 1.573935306 & up \\
\hline ORM1 & 2.927589001 & 0.030961761 & 1.549713031 & up \\
\hline HLA-G & 2.849204003 & 0.002217453 & 1.510558923 & up \\
\hline
\end{tabular}


bioRxiv preprint doi: https://doi.org/10.1101/2020.06.21.162990; this version posted June 22, 2020. The copyright holder for this preprint (which was not certified by peer review) is the author/funder, who has granted bioRxiv a license to display the preprint in perpetuity. It is made available under aCC-BY-NC-ND 4.0 International license.

\begin{tabular}{|c|c|c|c|c|}
\hline CNTRL & 2.797393023 & 0.038654594 & 1.484082961 & up \\
\hline NT5C3A & 2.786961002 & 0.029809971 & 1.478692815 & up \\
\hline FCGR1A;FCGR1B & 2.729613063 & 0.027523866 & 1.448696456 & up \\
\hline UBE2H & 2.675660552 & 0.016544392 & 1.4198951 & up \\
\hline IGHG1 & 2.667342941 & 0.004391802 & 1.415403324 & up \\
\hline RNASEL & 2.66589738 & 0.01356241 & 1.414621247 & up \\
\hline LAP3 & 2.665017027 & 0.000643916 & 1.414144751 & up \\
\hline DTX3L & 2.627024906 & $9.1292 \mathrm{E}-06$ & 1.393429878 & up \\
\hline DDX60 & 2.582397661 & 0.001981857 & 1.368711177 & up \\
\hline HLA-F & 2.578545022 & 0.00194924 & 1.366557235 & up \\
\hline APOBEC 3A & 2.562580893 & 0.00014281 & 1.357597547 & up \\
\hline UBE2L6 & 2.498977986 & $5.3001 \mathrm{E}-06$ & 1.321338193 & up \\
\hline IFIH1 & 2.476744865 & 0.02476334 & 1.308445261 & up \\
\hline PLEKHO1 & 2.469821785 & 0.013857145 & 1.304406945 & up \\
\hline TAPBP & 2.42632635 & 0.006722132 & 1.278773611 & up \\
\hline PARP10 & 2.378164111 & 0.006931352 & 1.249848275 & up \\
\hline OAS2 & 2.374963438 & 0.000172408 & 1.247905304 & up \\
\hline NMRAL1 & 2.374627701 & 0.030701143 & 1.247701342 & up \\
\hline WARS & 2.349807337 & 0.027942097 & 1.232542474 & up \\
\hline MT2A & 2.33286858 & 0.011742798 & 1.222105037 & up \\
\hline MX2 & 2.264411018 & 7.17913E-05 & 1.179135849 & up \\
\hline CMPK2 & 2.234466126 & 0.000927753 & 1.159930174 & up \\
\hline SLFN5 & 2.211552548 & 0.001790941 & 1.145059522 & up \\
\hline STEAP4 & 2.203861872 & 0.000871412 & 1.140033805 & up \\
\hline TAP1 & 2.201892681 & 0.000263078 & 1.138744154 & up \\
\hline CRELD2 & 2.194980102 & 0.001899455 & 1.134207862 & up \\
\hline LGALS2 & 2.188804925 & 0.000376489 & 1.130143382 & up \\
\hline HSP90AA4P & 2.153193532 & 0.047833126 & 1.106477996 & up \\
\hline MMAB & 2.141635594 & 0.00160927 & 1.098713022 & up \\
\hline VWF & 2.10859143 & 0.022518007 & 1.076279579 & up \\
\hline PARP14 & 2.044902897 & 0.000194978 & 1.032032338 & up \\
\hline ISG15 & 2.022046734 & 0.003291857 & 1.015816342 & up \\
\hline SETX & 2.016899828 & 0.029259053 & 1.012139433 & up \\
\hline IFIT5 & 2.007993136 & 0.032811277 & 1.005754337 & up \\
\hline NMI & 1.97225511 & $1.99399 \mathrm{E}-05$ & 0.979846176 & up \\
\hline NCAPG & 1.951870087 & 0.020042167 & 0.964857033 & up \\
\hline EIF2AK2 & 1.947305082 & 4.55981E-05 & 0.961478927 & up \\
\hline STAT2 & 1.934558553 & 0.000131581 & 0.952004395 & up \\
\hline IFI35 & 1.919285166 & 0.000195431 & 0.940569082 & up \\
\hline GNB3 & 1.916411372 & 0.012717112 & 0.93840728 & up \\
\hline CRYZ & 1.909069275 & 0.001752804 & 0.932869455 & up \\
\hline NCAPD2 & 1.908740424 & 0.013098805 & 0.932620919 & up \\
\hline TBC1D2B & 1.874865265 & 0.040970066 & 0.906786922 & up \\
\hline SOD2 & 1.872632974 & 0.044839145 & 0.905068167 & up \\
\hline ITPR3 & 1.858205539 & 0.042923999 & 0.893910089 & up \\
\hline TFRC & 1.857097277 & 0.030024606 & 0.893049387 & up \\
\hline GSDMD & 1.84689343 & 0.001387899 & 0.885100622 & up \\
\hline PML & 1.841301836 & 0.007924463 & 0.880726141 & up \\
\hline
\end{tabular}


bioRxiv preprint doi: https://doi.org/10.1101/2020.06.21.162990; this version posted June 22, 2020. The copyright holder for this preprint (which was not certified by peer review) is the author/funder, who has granted bioRxiv a license to display the preprint in perpetuity. It is made available under aCC-BY-NC-ND 4.0 International license.

\begin{tabular}{|c|c|c|c|c|}
\hline TAP2 & 1.840650416 & 0.000152784 & 0.88021565 & up \\
\hline PSTPIP2 & 1.835092454 & 0.02422987 & 0.87585275 & up \\
\hline UBE2J1 & 1.830609451 & 0.006339223 & 0.872324034 & up \\
\hline IRF9 & 1.830190882 & 0.000825242 & 0.871994124 & up \\
\hline RNF213 & 1.810606636 & 0.000103502 & 0.856473147 & up \\
\hline PPP1R3D & 1.804321022 & 0.008009343 & 0.851456044 & up \\
\hline CELF1 & 1.799042603 & 0.004077589 & 0.847229352 & up \\
\hline PSME2 & 1.796438968 & 0.001919177 & 0.845139922 & up \\
\hline APOBEC3G & 1.783021205 & 0.009988425 & 0.834323861 & up \\
\hline CAMK2D & 1.780022308 & 0.007047045 & 0.831895322 & up \\
\hline MCM7 & 1.765927068 & 0.000575721 & 0.820425762 & up \\
\hline OAS1 & 1.765920774 & 0.004909145 & 0.82042062 & up \\
\hline $\mathrm{ACP} 2$ & 1.760429687 & 0.014491586 & 0.815927606 & up \\
\hline NAMPT & 1.753134514 & 0.009543572 & 0.809936695 & up \\
\hline ACSL1 & 1.752492966 & 0.000312236 & 0.809408654 & up \\
\hline MCM4 & 1.746220328 & 0.00101539 & 0.804235601 & up \\
\hline $\mathrm{ABI} 3$ & 1.734958949 & 0.004601746 & 0.794901527 & up \\
\hline SMC4 & 1.734488474 & 0.002271406 & 0.794510254 & up \\
\hline ALDH18A1 & 1.703630539 & 0.016940962 & 0.768612496 & up \\
\hline TYMP & 1.684250725 & $3.44273 \mathrm{E}-05$ & 0.75210692 & up \\
\hline HLA-DRA & 1.681950991 & 0.000555157 & 0.750135668 & up \\
\hline PSMB9 & 1.678892033 & 0.006222961 & 0.747509456 & up \\
\hline LSM7 & 1.67484771 & 0.002745635 & 0.74402992 & up \\
\hline CMTR1 & 1.665714966 & 0.034154025 & 0.736141551 & up \\
\hline USP25 & 1.657294891 & 0.044572952 & 0.728830331 & up \\
\hline HLA-E & 1.651626027 & 0.040130399 & 0.723887058 & up \\
\hline ANO10 & 1.634510434 & 0.010483854 & 0.708858587 & up \\
\hline HTATIP2 & 1.613324875 & 0.006430347 & 0.690036983 & up \\
\hline DDX58 & 1.61022717 & 0.009963284 & 0.687264237 & up \\
\hline CD46 & 1.600228185 & 0.024394041 & 0.678277641 & up \\
\hline VPS37C & 1.599915122 & 0.043633022 & 0.67799537 & up \\
\hline GNB2 & 1.588595059 & 0.015493425 & 0.667751421 & up \\
\hline MCMBP & 1.586543378 & 0.000224296 & 0.665886967 & up \\
\hline SQRDL & 1.573405761 & 0.000651139 & 0.653890771 & up \\
\hline STX6 & 1.566817117 & 0.028750666 & 0.647836794 & up \\
\hline CYFIP2 & 1.564861267 & 0.025757535 & 0.646034761 & up \\
\hline TEP1 & 1.56103878 & 0.033605169 & 0.642506377 & up \\
\hline DYSF & 1.557578946 & 0.000654824 & 0.639305288 & up \\
\hline FCER1G & 1.552637403 & 0.010547745 & 0.634720948 & up \\
\hline MVP & 1.552363458 & 0.000266966 & 0.634466378 & up \\
\hline PIK3AP1 & 1.543746052 & 0.003380781 & 0.626435447 & up \\
\hline MYOF & 1.541172489 & 0.000146735 & 0.624028338 & up \\
\hline MCM2 & 1.519184388 & 0.006390223 & 0.603296985 & up \\
\hline MCM5 & 1.511816981 & 0.003753283 & 0.596283499 & up \\
\hline PSME1 & 1.508346011 & 0.000148199 & 0.592967417 & up \\
\hline MCM6 & 1.502258003 & 0.001730167 & 0.587132607 & up \\
\hline MAP2K2 & 1.500902674 & 0.041215499 & 0.585830428 & up \\
\hline
\end{tabular}


bioRxiv preprint doi: https://doi.org/10.1101/2020.06.21.162990; this version posted June 22, 2020. The copyright holder for this preprint (which was not certified by peer review) is the author/funder, who has granted bioRxiv a license to display the preprint in perpetuity. It is made available under aCC-BY-NC-ND 4.0 International license.

\begin{tabular}{|c|c|c|c|c|}
\hline PDLIM7 & 0.663445859 & 0.022542168 & -0.591949357 & down \\
\hline BLVRB & 0.654389255 & 0.000282335 & -0.611779036 & down \\
\hline PPT1 & 0.644878437 & 0.011465341 & -0.632900865 & down \\
\hline WDR81 & 0.638660073 & 0.041787404 & -0.646879835 & down \\
\hline NDUFAF2 & 0.631862851 & 0.015330496 & -0.662316647 & down \\
\hline COX6A1 & 0.629359433 & 0.01522108 & -0.668043905 & down \\
\hline MAVS & 0.626522534 & 0.000306839 & -0.674561695 & down \\
\hline TNFAIP8L2 & 0.625945689 & 0.023290714 & -0.67589061 & down \\
\hline TFEB & 0.620402779 & 0.017302062 & -0.688722947 & down \\
\hline EIF2D & 0.60563672 & 0.02551498 & -0.723475415 & down \\
\hline MT-CO3 & 0.598105602 & 0.039999944 & -0.741527864 & down \\
\hline CD180 & 0.592631322 & 0.006138699 & -0.754793217 & down \\
\hline LSM12 & 0.581077365 & 0.04773602 & -0.783197838 & down \\
\hline NUDT1 & 0.578283642 & 0.006310817 & -0.790150803 & down \\
\hline ELAC2 & 0.576827742 & 0.028826204 & -0.793787544 & down \\
\hline SLAIN2 & 0.573970435 & 0.041772694 & -0.800951668 & down \\
\hline HIP1 & 0.565320558 & 0.00576678 & -0.822858933 & down \\
\hline SULT1A1;SULT1A2 & 0.556778326 & 0.026237365 & -0.844825042 & down \\
\hline NUP43 & 0.553500944 & 0.016482015 & -0.853342317 & down \\
\hline SULT1A4;SULT1A3 & 0.548695133 & 0.004076336 & -0.865923315 & down \\
\hline FIP1L1 & 0.548520965 & 0.004696804 & -0.866381333 & down \\
\hline SERPINB10 & 0.53578529 & 0.001976571 & -0.900273121 & down \\
\hline TXNRD2 & 0.533166565 & 0.011072804 & -0.907341784 & down \\
\hline ALDH1B1 & 0.519596732 & 0.02647659 & -0.944535738 & down \\
\hline EEPD1 & 0.515340263 & 0.019062957 & -0.956402783 & down \\
\hline CD163 & 0.501320557 & 0.000219738 & -0.996194702 & down \\
\hline MVD & 0.499521278 & 0.00312502 & -1.001381962 & down \\
\hline ZNF185 & 0.494753377 & 0.003090267 & -1.015218539 & down \\
\hline PON2 & 0.493596674 & 0.020855696 & -1.018595422 & down \\
\hline CD93 & 0.489563112 & 0.0023838 & -1.030433238 & down \\
\hline SERPINB6 & 0.478329594 & 0.026444784 & -1.063923042 & down \\
\hline KDELC2 & 0.470443913 & 0.000246391 & -1.087905363 & down \\
\hline RBP7 & 0.467447152 & 0.000407145 & -1.097124827 & down \\
\hline PRKCA & 0.465139872 & 0.000357634 & -1.104263481 & down \\
\hline SCAF8 & 0.450868365 & 0.003900932 & -1.149221809 & down \\
\hline RNF214 & 0.449683772 & 0.040045001 & -1.153017272 & down \\
\hline PHRF1 & 0.448849367 & 0.038284086 & -1.155696733 & down \\
\hline RAB43 & 0.447602621 & 0.034978808 & -1.159709611 & down \\
\hline PSMB6 & 0.444148814 & 0.004007442 & -1.170884957 & down \\
\hline SCLY & 0.402078844 & 0.039509085 & -1.314449667 & down \\
\hline VAMP2 & 0.394010528 & 0.002778059 & -1.343693915 & down \\
\hline VSTM1 & 0.389293906 & 0.019859103 & -1.361068333 & down \\
\hline SEC61G & 0.386381738 & 0.017899298 & -1.371901187 & down \\
\hline DHX30 & 0.385584951 & 0.004487398 & -1.374879348 & down \\
\hline UBQLN4 & 0.38380104 & 0.019040313 & -1.381569476 & down \\
\hline KAT7 & 0.372740082 & 0.013291966 & -1.42375813 & down \\
\hline F11R & 0.369554963 & 0.004550265 & -1.436139146 & down \\
\hline CCBL2 & 0.347215706 & 0.005611791 & -1.526095887 & down \\
\hline
\end{tabular}


bioRxiv preprint doi: https://doi.org/10.1101/2020.06.21.162990; this version posted June 22, 2020. The copyright holder for this preprint (which was not certified by peer review) is the author/funder, who has granted bioRxiv a license to display the preprint in perpetuity. It is made available under aCC-BY-NC-ND 4.0 International license.

\begin{tabular}{|c|c|c|c|c|}
\hline CD33 & 0.341430701 & 0.002080955 & -1.550335305 & down \\
\hline SNX8 & 0.337181672 & 0.032861444 & -1.568401977 & down \\
\hline NIPSNAP3A & 0.336777473 & 0.028350659 & -1.570132453 & down \\
\hline TPM4 & 0.318603202 & 0.033985693 & -1.650167331 & down \\
\hline FXR2 & 0.294721975 & 0.010302871 & -1.762573459 & down \\
\hline CRTC3 & 0.293884166 & 0.047636881 & -1.766680464 & down \\
\hline KIF13A & 0.293423924 & 0.044497379 & -1.768941592 & down \\
\hline CD99 & 0.286740335 & 0.005670445 & -1.802183234 & down \\
\hline COA4 & 0.284491998 & 0.033815571 & -1.813540023 & down \\
\hline QSOX1 & 0.276051541 & 0.014255911 & -1.856990439 & down \\
\hline RGPD3;RGPD4 & 0.273010423 & 0.016628872 & -1.872972062 & down \\
\hline DAG1 & 0.269765269 & 0.041724865 & -1.890223477 & down \\
\hline RRP8 & 0.268240751 & 0.009931979 & -1.898399666 & down \\
\hline MAP2K6 & 0.243003422 & 0.000139823 & -2.040951464 & down \\
\hline TMSB15B;TMSB15A & 0.224375929 & 0.006398954 & -2.156010182 & down \\
\hline SLC9A9 & 0.212873085 & 0.017959461 & -2.231934542 & down \\
\hline GTPBP2 & 0.202188123 & 0.040327029 & -2.306229843 & down \\
\hline EMILIN1 & 0.198031353 & 0.028678035 & -2.336199235 & down \\
\hline AHR & 0.180282269 & 0.021406649 & -2.471670581 & down \\
\hline ZC3H18 & 0.173180939 & 0.008805046 & -2.529647941 & down \\
\hline GANC & 0.171008188 & 0.003143901 & -2.547862691 & down \\
\hline ATP2B1 & 0.166786666 & 0.010723861 & -2.583924142 & down \\
\hline & 0.161260159 & 0.031524997 & -2.632538046 & down \\
\hline ARPIN;C15orf38-AP3S2 & 0.155712384 & 0.000866374 & -2.683044407 & down \\
\hline TUBA8 & 0.132987339 & 0.035928117 & -2.910639197 & down \\
\hline PRG3 & 0.130771913 & 0.04294544 & -2.934875383 & down \\
\hline CCR2 & 0.116746002 & 0.022859969 & -3.098554949 & down \\
\hline RAB12 & 0.115502757 & 0.025796438 & -3.114000806 & down \\
\hline LY86 & 0.110404382 & 0.047996962 & -3.179130654 & down \\
\hline CECR1 & 0.076149082 & $1.99576 \mathrm{E}-05$ & -3.715029548 & down \\
\hline LY6G6F & 0.067776884 & 0.008992576 & -3.883062874 & down \\
\hline ABAT & 0 & 0.035279301 & N/A & down \\
\hline ALOX15B & 0 & 0.03770116 & N/A & down \\
\hline CCBL1 & 0 & 0.04587953 & N/A & down \\
\hline CD99 & 0 & 0.037487884 & N/A & down \\
\hline CHD8 & 0 & 0.043669172 & N/A & down \\
\hline CIRH1A & 0 & 0.038531897 & N/A & down \\
\hline СРТP & 0 & 0.032966997 & N/A & down \\
\hline CYB5A & 0 & 0.044516561 & N/A & down \\
\hline DAAM1 & 0 & 0.037253706 & N/A & down \\
\hline DNAAF5 & 0 & 0.029205907 & N/A & down \\
\hline GPR107 & 0 & 0.035517551 & N/A & down \\
\hline KLHL36 & 0 & 0.035885722 & N/A & down \\
\hline MARK3;MARK1 & 0 & 0.035439205 & N/A & down \\
\hline MRPL43 & 0 & 0.010537642 & N/A & down \\
\hline NFRKB & 0 & 0.013386263 & N/A & down \\
\hline PHLDB3 & 0 & 0.038382433 & N/A & down \\
\hline PPP2R2D & 0 & 0.044977766 & N/A & down \\
\hline
\end{tabular}




\begin{tabular}{|l|l|c|c|l|}
\hline PSEN1 & 0 & 0.021371401 & N/A & down \\
\hline SP2 & 0 & 0.03644088 & N/A & down \\
\hline
\end{tabular}

Table S1. Proteins significantly up or downregulated in proteomes from DADA2 monocytes in comparison with healthy donors controls

\section{Supplementary Table 2}

\begin{tabular}{|c|c|c|c|}
\hline Symptom & $\begin{array}{c}\text { ADA1 } \\
\text { deficiency }\end{array}$ & $\begin{array}{c}\text { ADA2 } \\
\text { deficiency }\end{array}$ & $\begin{array}{c}\text { DNAseII } \\
\text { deficiency }\end{array}$ \\
\hline Age of onset & $<6$ months & Variable & Variable \\
\hline Absence of lymph node germinal centers & Frequent & N.R. & N.R. \\
\hline Absent tonsils & Frequent & N.R. & N.R. \\
\hline Allergy & Frequent & Variable & Variable \\
\hline B- lymphocytopenia & Frequent & Frequent & Rare \\
\hline Decrease in t cell count & Frequent & Rare & Variable \\
\hline Chronic Diarrhea & Frequent & Variable & Variable \\
\hline Failure to thrive & Frequent & Variable & Variable \\
\hline Increased circulating total IgE level & Frequent & Variable & Frequent \\
\hline Diffuse rash & Frequent & Rare & Variable \\
\hline Livedo racemosa & Rare & Frequent & Variable \\
\hline Purpura & Rare & Frequent & Variable \\
\hline Recurrent otitis media & Frequent & Variable & Variable \\
\hline Recurrent pneumonia & Frequent & Variable & Variable \\
\hline Recurrent respiratory tract infections & Frequent & Variable & Frequent \\
\hline Sinusitis & Frequent & Variable & Frequent \\
\hline Vasculitis & Rare & Frequent & Frequent \\
\hline Pancytopenia & Rare & Frequent & Frequent \\
\hline Anemia & Rare & Frequent & Frequent \\
\hline Digital ischemia & Rare & Frequent & Frequent \\
\hline Ischemic stroke & Rare & Frequent & Frequent \\
\hline Glomerulopathy & Rare & Frequent & \\
\hline Arthropathy & Rare & Rare & \\
\hline
\end{tabular}

Table S.2: Comparison of the main clinical signs and symptoms observed respectively in ADA1 deficiency, ADA2 deficiency and DNAseII deficiency. 


\section{Supplementary Table 3}

\begin{tabular}{|c|c|c|}
\hline Construct & Small scale & $\begin{array}{c}\text { Large scale\# } \\
\text { (IMAC only/IMAC+SEC) }\end{array}$ \\
\hline M243R & 0.03 & \\
\hline G321E & 0.04 & \\
\hline Domain aa29-465 & 0.05 & \\
\hline Domain aa29-191 & 0.08 & \\
\hline Domain aa96-511 & 0.09 & \\
\hline L311R & 0.10 & \\
\hline Deletion aa170-177 & 0.11 & \\
\hline T129P & 0.12 & \\
\hline V458D & 0.13 & \\
\hline aa132-511 & 0.13 & \\
\hline I93T & 0.14 & \\
\hline F178S & 0.18 & \\
\hline M445K & 0.31 & \\
\hline L249P & 0.31 & $5.4 / 2.9$ \\
\hline G47R & 0.45 & \\
\hline G47A & & $12 / *$ \\
\hline P193L & 0.47 & $5.2 / 2.7$ \\
\hline E328K & 0.6 & \\
\hline G358R & 0.92 & $7.7 / 1.5$ \\
\hline Y168A & 0.96 & $13.2 / 10.6$ \\
\hline Domain aa47-511 & 0.97 & $12.1 / 4.6$ \\
\hline P344L & 1.23 & \\
\hline K170A & 2.1 & \\
\hline ADA2 Wt & 2.61 & $28.6 / 7.6$ \\
\hline R171A & 2.8 & $33.4 / 29.1$ \\
\hline
\end{tabular}

Table S.3: Expression yields of ADA2 mutants. For screening in small scale expression each mutant construct was produced in $100 \mathrm{ml}$ final volume. Final expression yield after IMAC purification are noted in $\mathrm{mg}$. For the large-scale expression, several structural mutants were selected but only mutants with yield above $0.4 \mathrm{mg}$ in small scale expression. Each of these mutants was produced in $1 \mathrm{~L}$ scale, purified via IMAC and SEC. Final yield in mg.* G47A, was not purified by SEC as it already had a high monomer content after IMAC purification. 


\section{BIBLIOGRAPHY}

1. R. J.C. et al., Social network architecture of human immune cells unveiled by quantitative proteomics. Nat Immunol. 18, 583-593 (2017).

2. J. Cox, M. Mann, MaxQuant enables high peptide identification rates, individualized p.p.b.-range mass accuracies and proteome-wide protein quantification. Nat. Biotechnol. 26, 1367-1372 (2008).

3. R Core Team, R Core Team (2014). R: A language and environment for statistical computing. R Found. Stat. Comput. Vienna, Austria. URL http//www.R-project.org/. (2014).

4. W. Huber et al., Orchestrating high-throughput genomic analysis with Bioconductor. Nat. Methods. 12, 115-121 (2015).

5. X. Zhang et al., Proteome-wide identification of ubiquitin interactions using UbIA-MS. Nat. Protoc. 13, 530-550 (2018).

6. H. Wickham, ggplot2: Elegant Graphics for Data Analysis. Springer-Verlag New York (2016).

7. D. W. Huang, B. T. Sherman, R. A. Lempicki, Systematic and integrative analysis of large gene lists using DAVID bioinformatics resources. Nat. Protoc. 4, 44-57 (2009).

8. P. Shannon et al., Cytoscape: A software Environment for integrated models of biomolecular interaction networks. Genome Res., 2498-2504 (2003).

9. S. Tripathi et al., Meta- and Orthogonal Integration of Influenza "oMICs" Data Defines a Role for UBR4 in Virus Budding. Cell Host Microbe. 18, 723-735 (2015).

10. E. F. Pettersen et al., UCSF Chimera - A visualization system for exploratory research and analysis. J. Comput. Chem. 25, 1605-1612 (2004).

11. Y. Perez-Riverol et al., The PRIDE database and related tools and resources in 2019: Improving support for quantification data. Nucleic Acids Res. (2019), doi:10.1093/nar/gky1106.

12. W. Yang et al., Glycoform analysis of recombinant and human immunodeficiency virus envelope protein gp120 via higher energy collisional dissociation and spectral-aligning strategy. Anal. Chem. 86, 6959-6967 (2014).

13. M. P. Rodero, Y. J. Crow, Type I interferon-mediated monogenic autoinflammation: The type I interferonopathies, a conceptual overview. J. Exp. Med. 213, 2527-2538 (2016).

14. Y. Zhang et al., An RNA-sequencing transcriptome and splicing database of glia, neurons, and vascular cells of the cerebral cortex. J. Neurosci. 34, 11929-11947 (2014).

15. P. Emsley, B. Lohkamp, W. G. Scott, K. Cowtan, Features and development of Coot. Acta Crystallogr. Sect. D Biol. Crystallogr. 66, 486-501 (2010). 
bioRxiv preprint doi: https://doi.org/10.1101/2020.06.21.162990; this version posted June 22, 2020. The copyright holder for this preprint (which was not certified by peer review) is the author/funder, who has granted bioRxiv a license to display the preprint in perpetuity. It is made available under aCC-BY-NC-ND 4.0 International license.

Fig. S.1

A

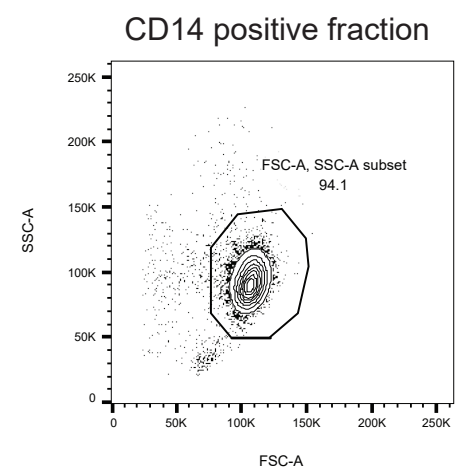

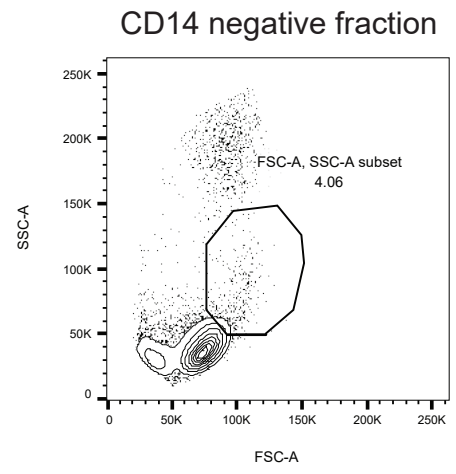

B

\begin{tabular}{|c|c|}
\hline Patient & Mutations \\
\hline $\mathbf{1}$ & $\mathrm{R} 169 \mathrm{Q} / \mathrm{M} 243 \mathrm{R}$ \\
\hline $\mathbf{2}$ & $\mathrm{V} 458 \mathrm{D} / \mathrm{N} 458 \mathrm{D}$ \\
\hline $\mathbf{3}$ & $\mathrm{c} .972+3 \mathrm{~A}>\mathrm{G} / \mathrm{c} .973-2 \mathrm{~A}>\mathrm{G}(\mathrm{g} .68297 \mathrm{~A}>\mathrm{G} / \mathrm{g} .69787 \mathrm{~A}>\mathrm{G})$ \\
\hline $\mathbf{4}$ & $\mathrm{G} 47 \mathrm{~A} / \mathrm{G} 47 \mathrm{~A}$ \\
\hline $\mathbf{5}$ & $\mathrm{C} 408 \mathrm{Y} / \mathrm{c} .542+1 \mathrm{G}>\mathrm{A}(\mathrm{g} .51166 \mathrm{G}>\mathrm{A})$ \\
\hline $\mathbf{6}$ & $\mathrm{c} .973-1 \mathrm{G}>\mathrm{A} / \mathrm{c} .973-1 \mathrm{G}>\mathrm{A}(\mathrm{g} .69788 \mathrm{G}>\mathrm{A})$ \\
\hline
\end{tabular}

C
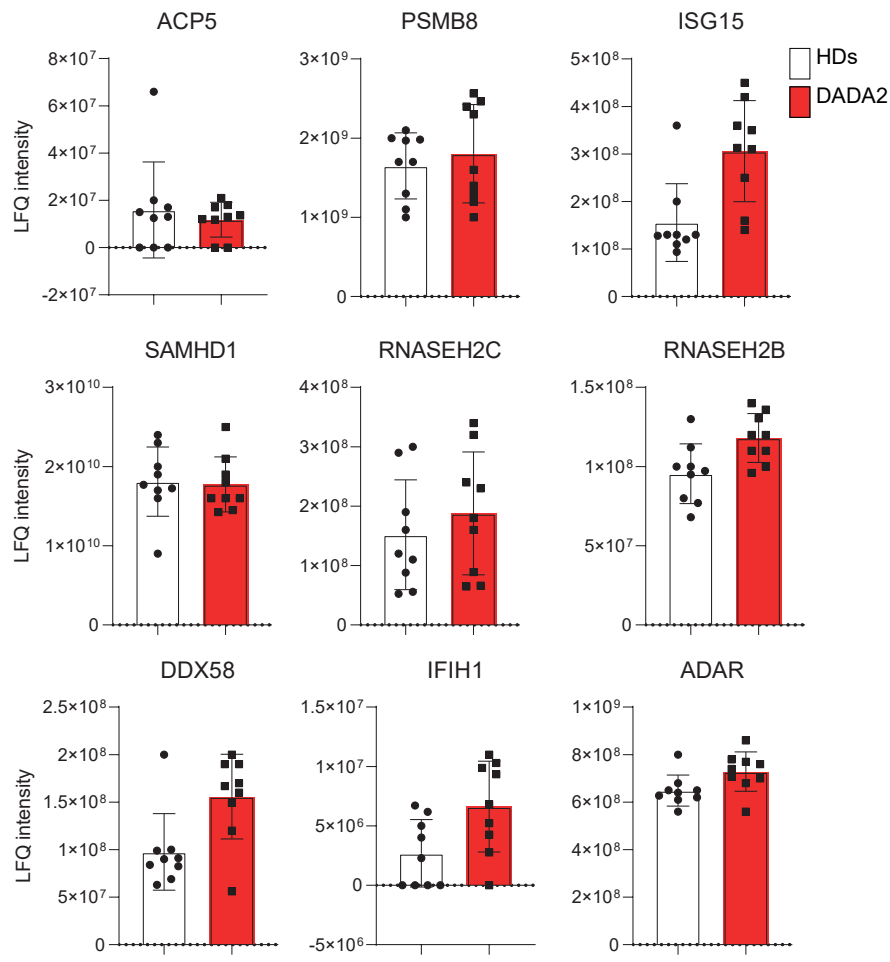

ADAR
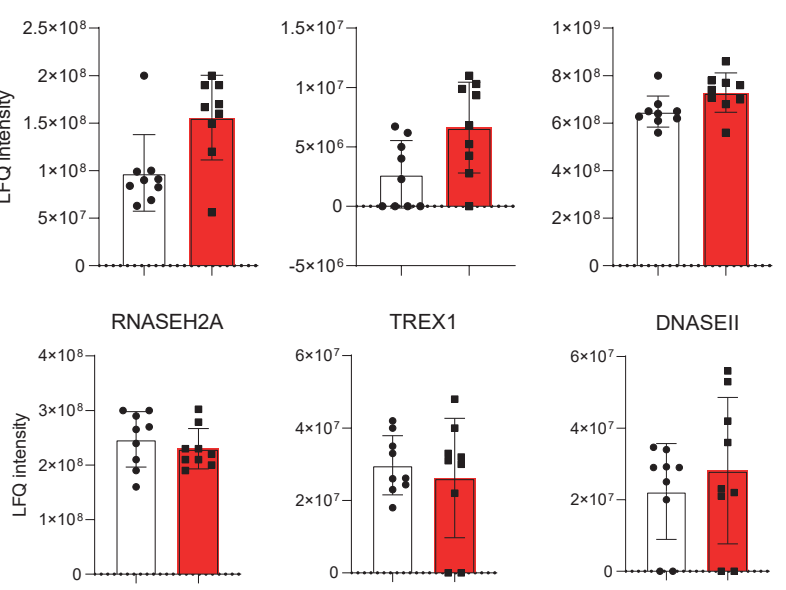
Greiner-Tollersrud O.K. et al.

Fig.S. 2

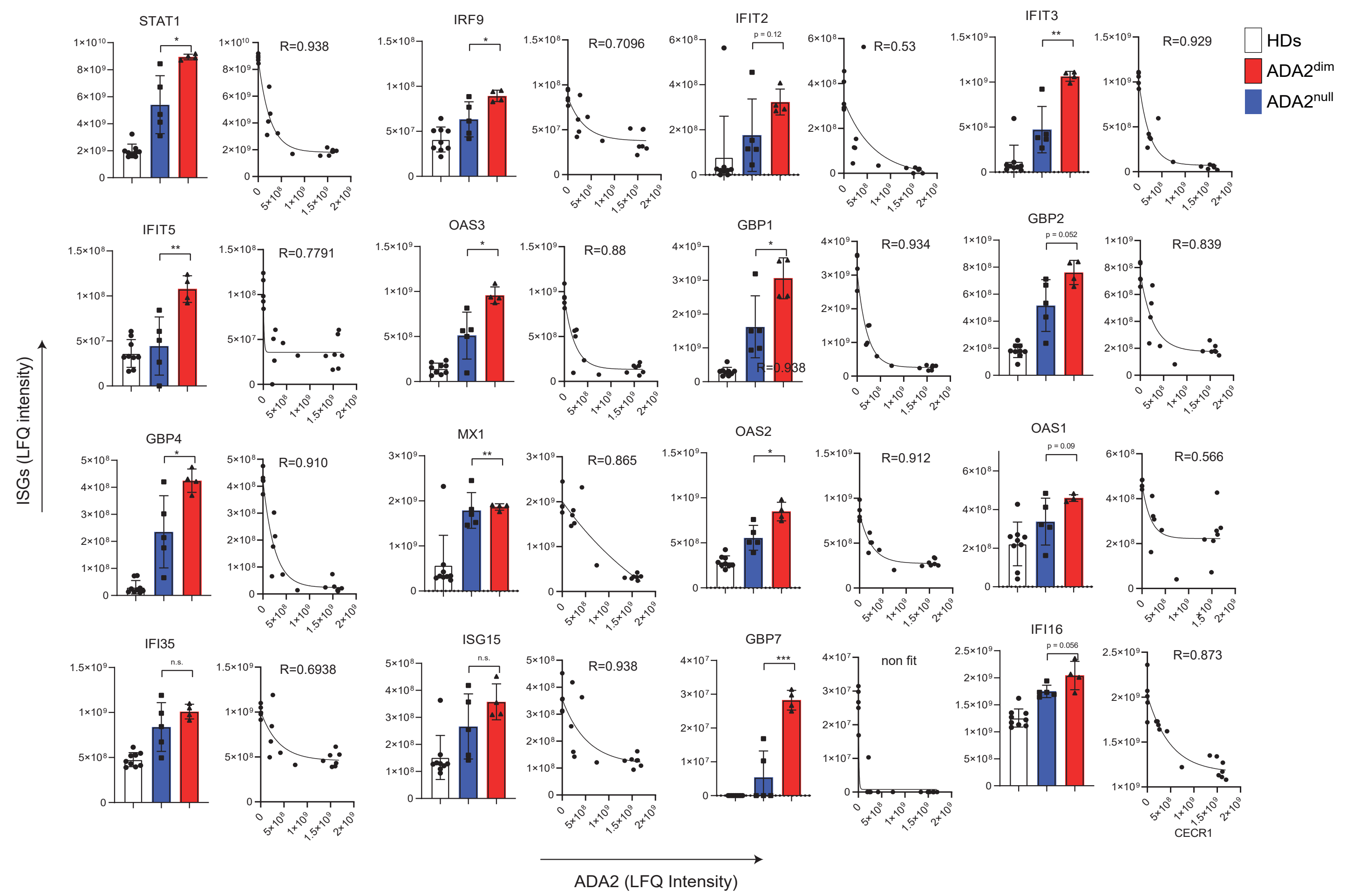


bioRxiv preprint doi: https://doi.org/10.1101/2020.06.21.162990; this version posted June 22, 2020. The copyright holder for this preprint

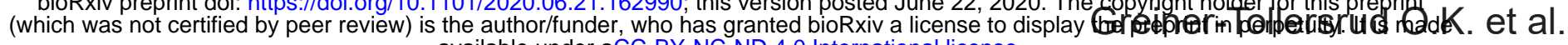
available under aCC-BY-NC-ND 4.0 International license.

Fig.S. 3

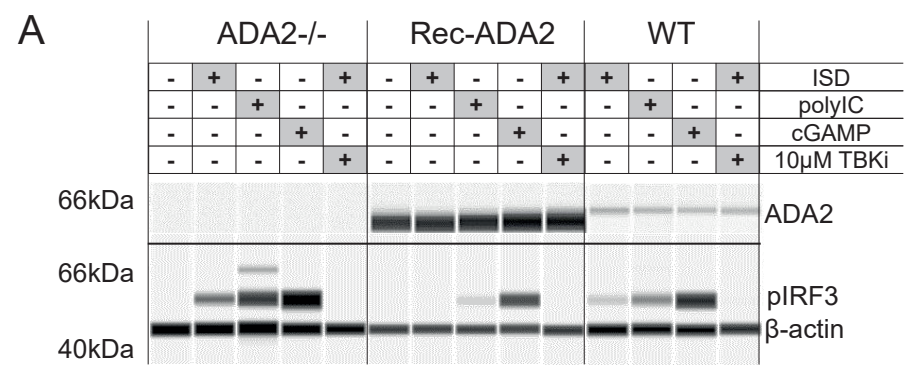

B

WT

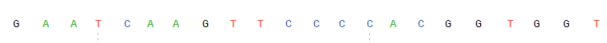

ADA2-/-

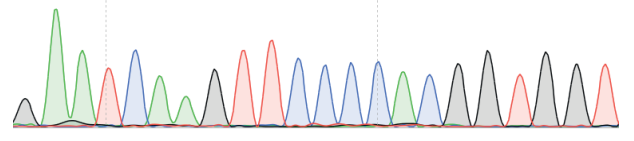

"Greinér-Tóllersrud Ó.K. et ål. Figure 3

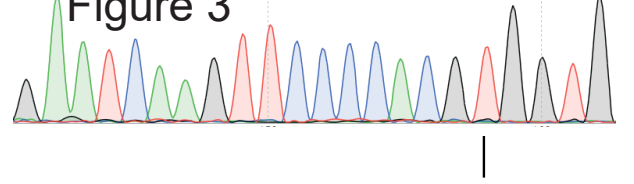

-1 del. T 


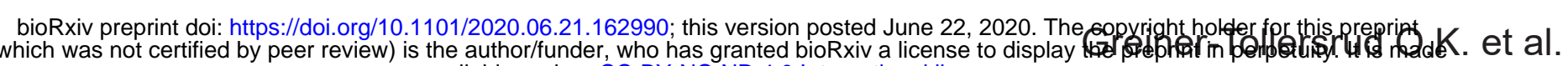
available under aCC-BY-NC-ND 4.0 International license.

Fig. S. 4

A

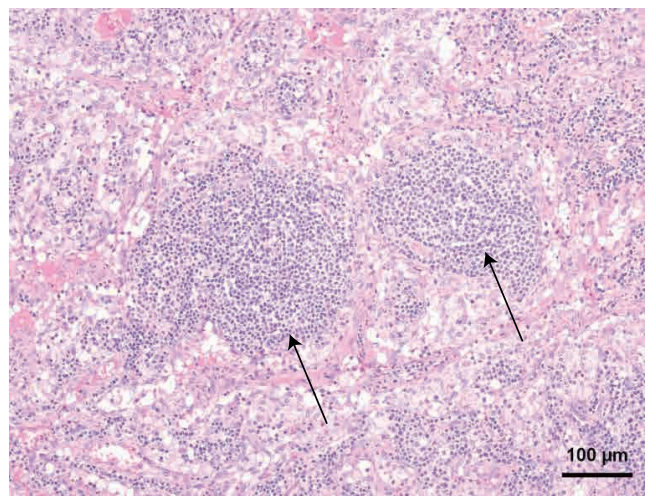

D

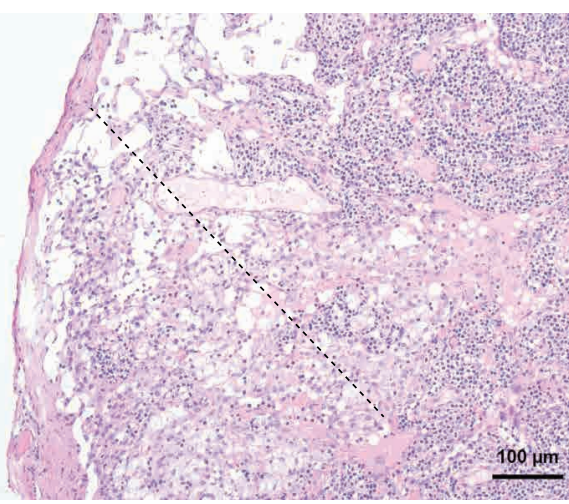

B

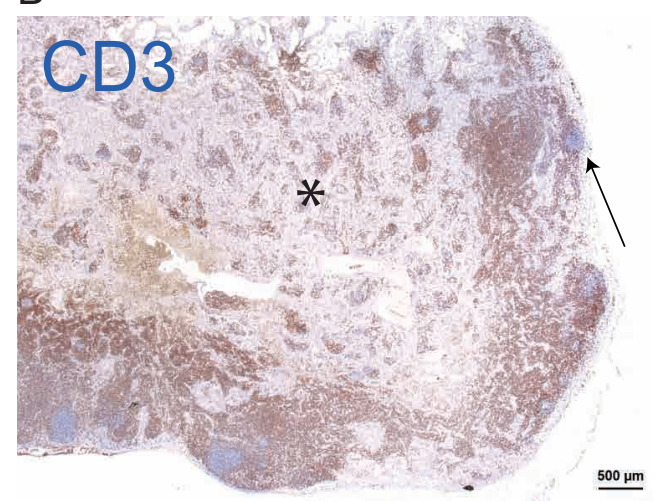

C

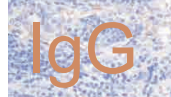

$100 \mu \mathrm{m}$
E

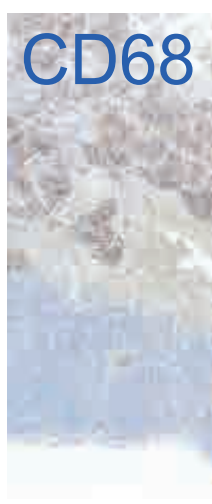

$\mathrm{F}$

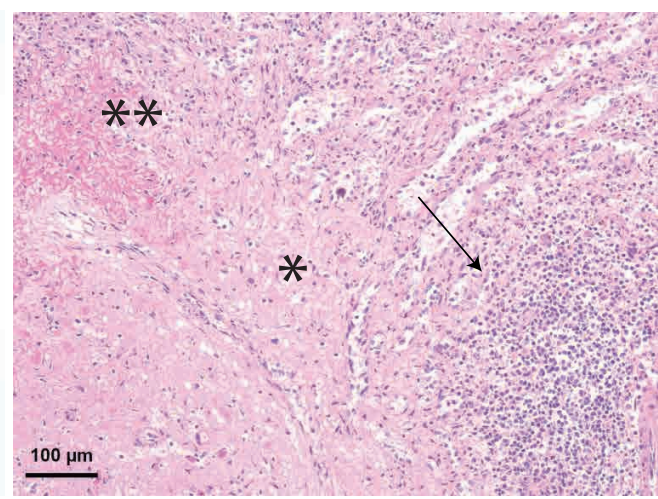

G
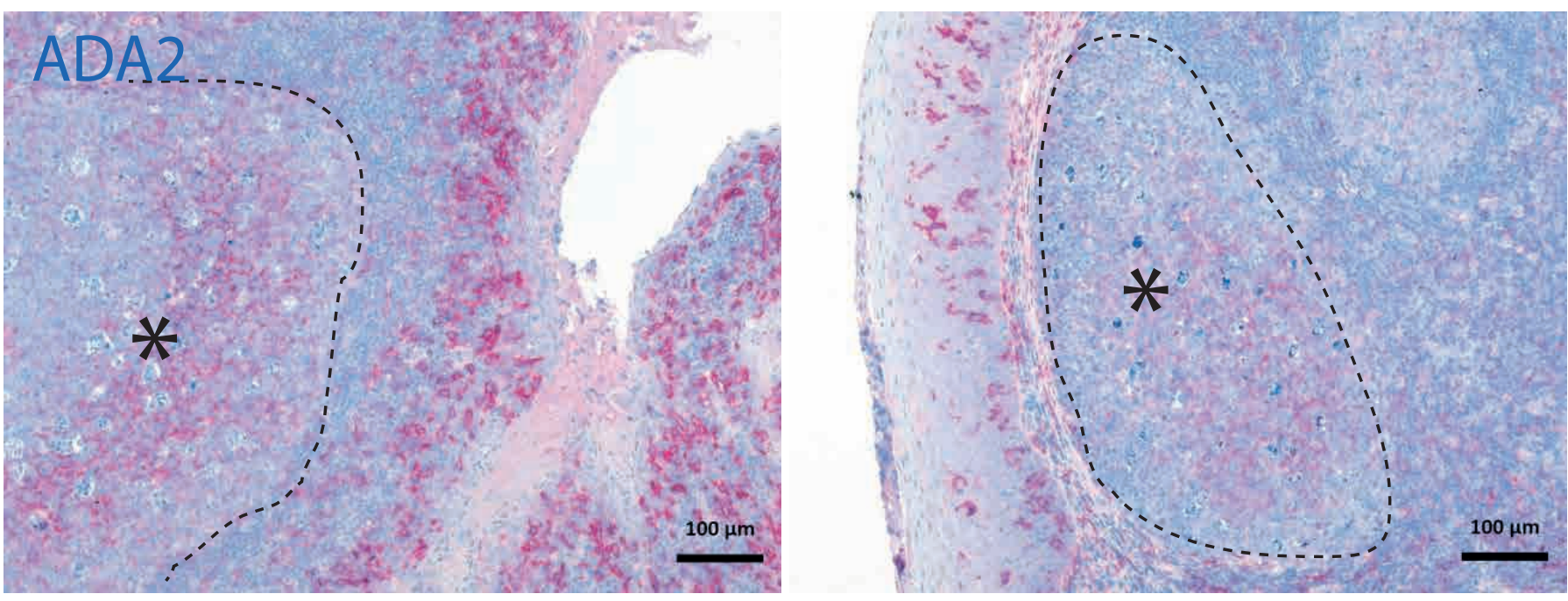

$\mathrm{H}$
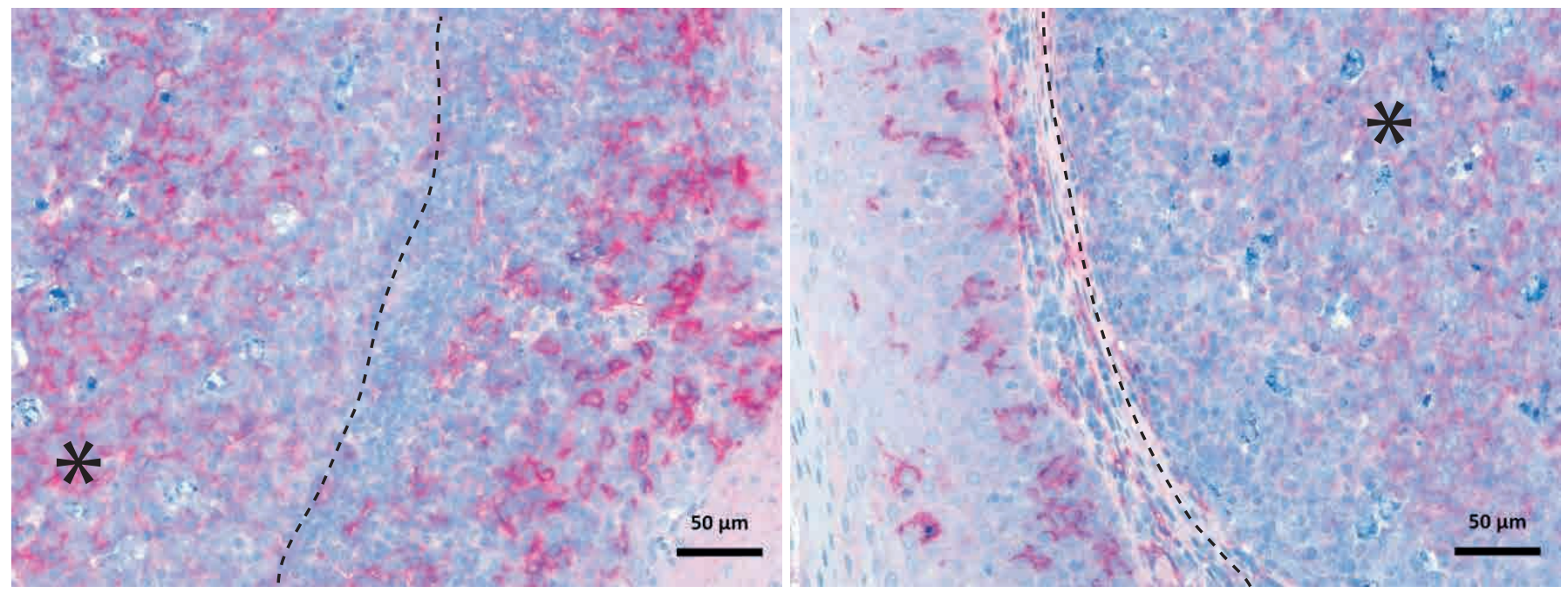
bioRxiv preprint doi: https://doi.org/10.1101/2020.06.21.162990; this version posted June 22, 2020. The copyright holder for this preprint

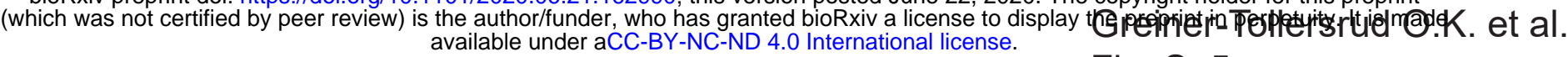

Fig. S. 5

A

Identities: 352/501(70\%)

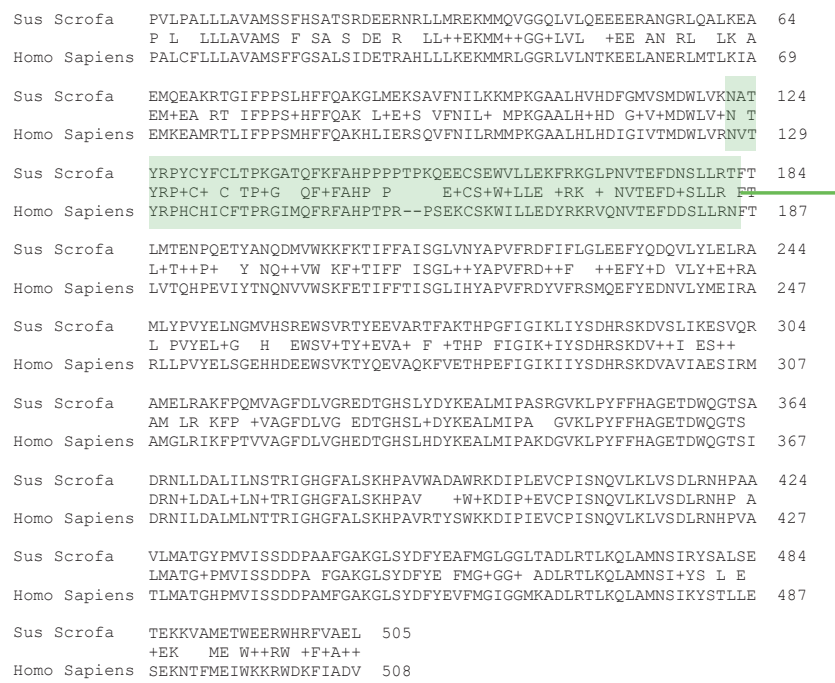

Sus Scrofa PVLPALLLAVAMSSFHSATSRDEERNRLIMREKMMQVGGQLVLQEEEERANGRLQALKEA 64

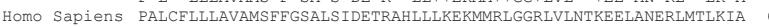

Sus Scrofa EMQEAKRTGIFPPSLHFEQAKGLMEKSAVFNILKKMPKGAALHVHDFGMVSMDWLVKNAT 12 Homo Sapiens EMKEAMRTLIFPPSMHFFQAKHLIERS OVFNILRMMPKGAALHLHDIGIVTMDWLVRNVT 12 Homo Sapiens RLLPVYELSGEHHDEEWSVKTYQEVAQKFVETHPEFIGIKIIYSDHRSKDVAVIAESIRM 307

Sus Scrofa AMELRAKFPQMVAGFDLVGREDTGHSLYDYKEALMIPASRGVKLPYFFHAGETDWQGTSA 364 Homo Sapiens AMGLRIKFPTVVAGFDLVGHEDTGHSLHDYKEALMI PAKDGVKLPYFFHAGETDWQGTSI 367

Sus Scrofa DRNLLDALILNSTRIGHGFALSKHPAVWADAWRKDI PLEVCPISNQVLKLVSDLRNHPAA 424 Homo Sapiens DRNILDALMLNTTRIGHGFALSKHPAVRTYSWKKDIPIEVCPISNQVLKLVSDLRNHPVA 427

Sus Scrofa VLMATGYPMVISSDDPAAFGAKGLSYDFYEAFMGLGGLTADLRTLKQLAMNSIRYSALSE 48 Homo Sapiens TLMATGHPMVISSDDPAMEGAKGISYDFYEVEMGTGCMKADIRTIKOLAMNSTKYSTLIE 487 Homo Sapiens SEKNTFMEIWKKRWDKFIADV 508

C

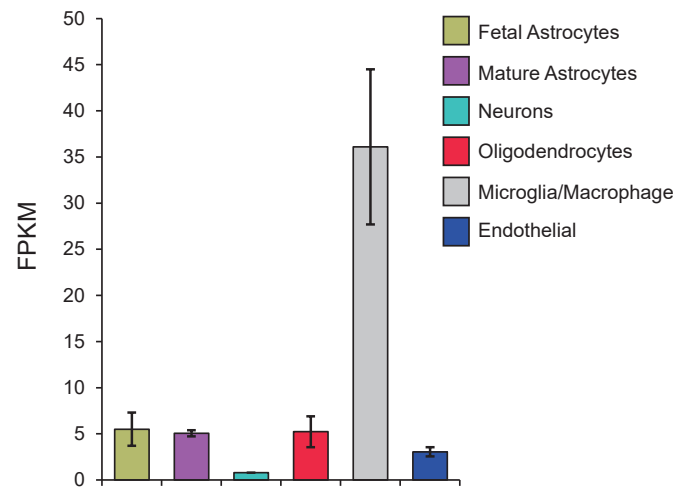

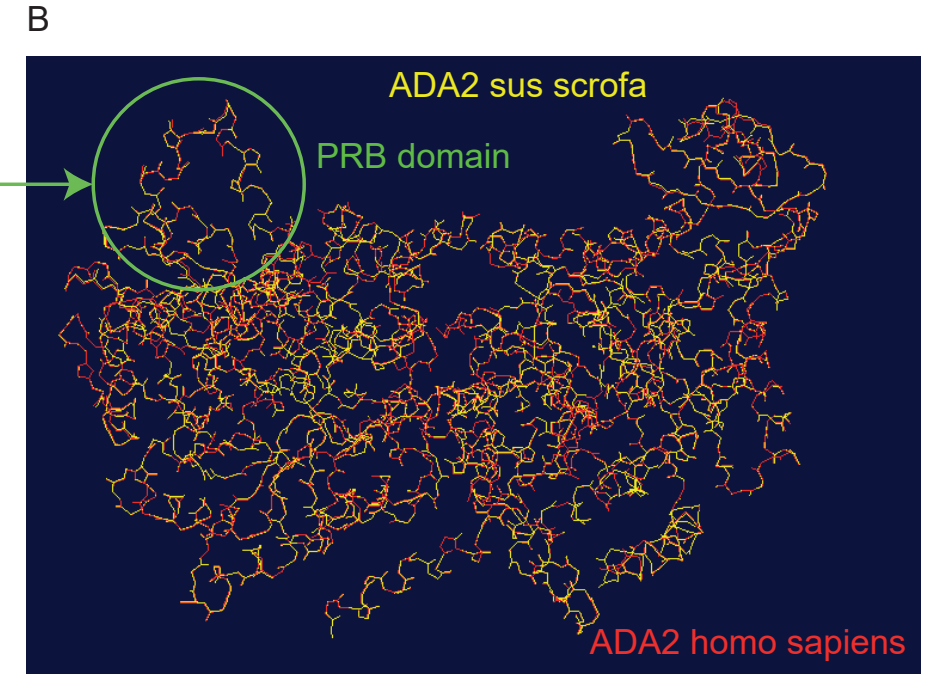

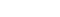


bioRxiv preprint doi: https://doi.org/10.1101/2020.06.21.162990; this version posted June 22, 2020. The copyright hetder for this prepxint

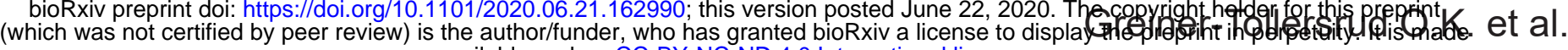

\section{A PIG BRAIN} available under aCC-BY-NC-ND 4.0 International license.

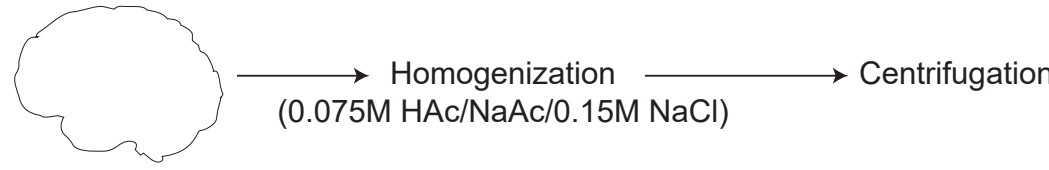

Fig. S. 6

(0.075M HAc/NaAc/0.15M NaCl)

$\rightarrow \quad$ Heat treatment $\left(\mathrm{pH} 7.6,60^{\circ} \mathrm{C} / 10 \mathrm{~min}\right)$
(3) DEAE anion exchange chromatography
Phosphate $0.05 \mathrm{M}$

Concanavalin A chromatography Elution at 0.2 M Methylmannoside

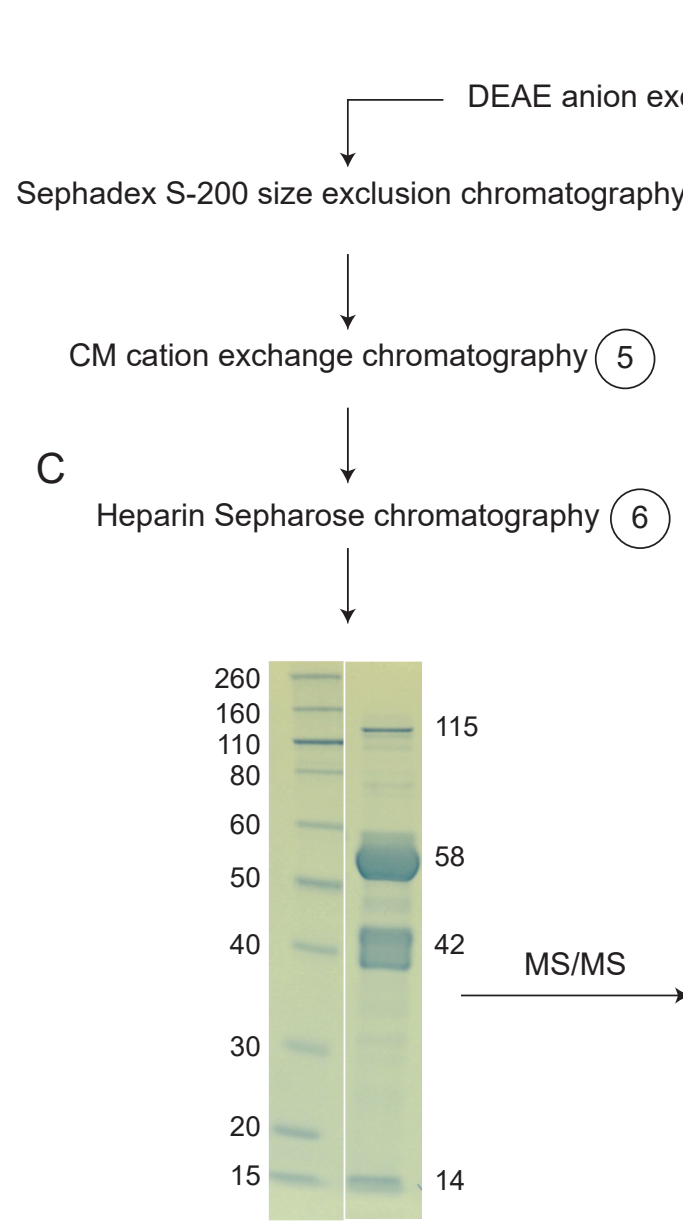

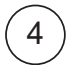

D Hydroxylapatite chromatography

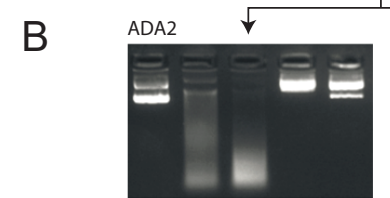

Phosphate [M] $\quad 0 \quad 0.05 \quad 0.1 \quad 0.15 \quad 0.2$

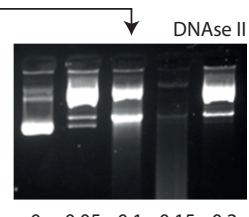

$\begin{array}{lllll}0 & 0.05 & 0.1 & 0.15 & 0.2\end{array}$
Protein name

115 Adenosine deaminase 2 (ADA2) Proliferating cell nuclear antigen
Accession \#

P58780 NP_001278854

58 Adenosine deaminase 2 (ADA2) Beta-galactosidase 1-like

Oligodendrocyte myelin glycoprotein Arylsulphatase B

\begin{tabular}{||l||l||l|}
\hline P58780 & 68741 & 2903.64 \\
XP_001928410 & 881 & 0.63 \\
Q63912 & 119 & 0.16 \\
P15848 & 106 & 0.27 \\
\hline
\end{tabular}

42 Adenosine deaminase 2 (ADA2) Arylsulphatase B

Noelin

Aspartate aminotransferase

Oligodendrocyte myelin glycoprotein Neurexin 3

\begin{tabular}{|c|c|c|}
\hline $\begin{array}{l}\text { P58780 } \\
\text { P15848 } \\
\text { Q62609 } \\
\text { P00506 } \\
\text { Q63912 } \\
\text { Q6P9K9 }\end{array}$ & \begin{tabular}{|l|}
3588 \\
5543 \\
753 \\
733 \\
519 \\
340 \\
\end{tabular} & $\begin{array}{l}30.87 \\
1.95 \\
1.64 \\
3.17 \\
1.38 \\
0.28 \\
\end{array}$ \\
\hline $\begin{array}{l}\text { P58780 } \\
\text { P15848 } \\
\text { P00883 } \\
\text { Q62609 } \\
\text { Q63912 } \\
\text { Q8HY81 }\end{array}$ & \begin{tabular}{|l|}
23679 \\
981 \\
733 \\
619 \\
597 \\
121
\end{tabular} & \begin{tabular}{|l}
12.80 \\
1.77 \\
4.07 \\
1.17 \\
1.06 \\
0.10
\end{tabular} \\
\hline
\end{tabular}

Adenosine deaminase 2 (ADA2)

Arylsulphatase B

Fructose-1-biphosphate aldolase A Noelin

Oligodendrocyte myelin glycoprotein Cathepsin 5

\section{Adenosine deaminase 2 (ADA2) Immunoglobulin lambda chain $C$ reg. Beta-galactosidase 1-like Arylsulphatase $\mathrm{B}$ Prostaglandin H2 D-isomerase}

\begin{tabular}{||l||l|l|}
\hline P58780 & 364 & 6.69 \\
P01846 & 1002 & 10.40 \\
XP_001928410 & 215 & 0.16 \\
P15848 & 176 & 0.43 \\
Q29095 & 164 & 0.40 \\
\hline
\end{tabular}

E
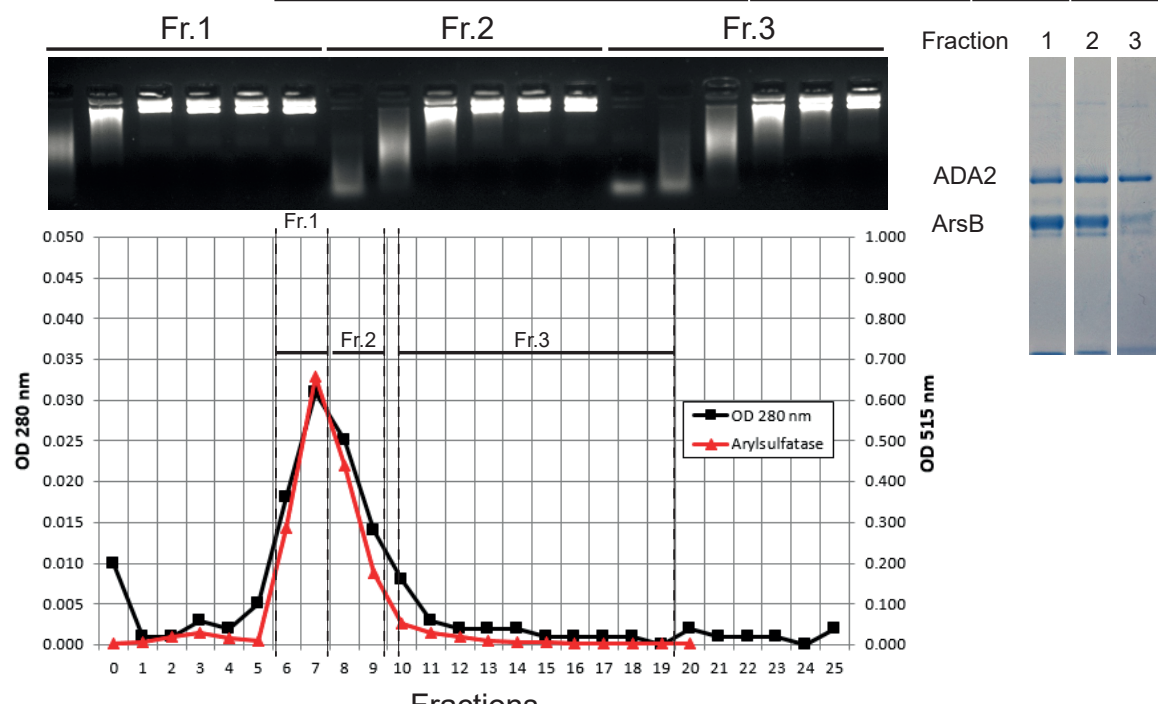

Fractions 
bioRxiv preprint doi: https://doi.org/10.1101/2020.06.21.162990; this version posted June 22, 2020. The copxright holder for this preprint

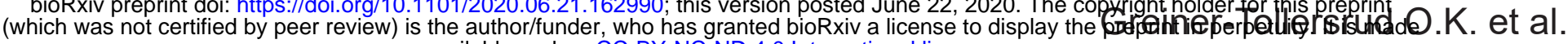
available under aCC-BY-NC-ND 4.0 International license.

Fig. S. 7

\begin{tabular}{llllllll} 
A & \multicolumn{1}{c}{ LFQ intenstiy } \\
18 & 20 & 22 & 24 & 26 & 28 & 30 & 32
\end{tabular}$\square$ Undetectable

Run 1

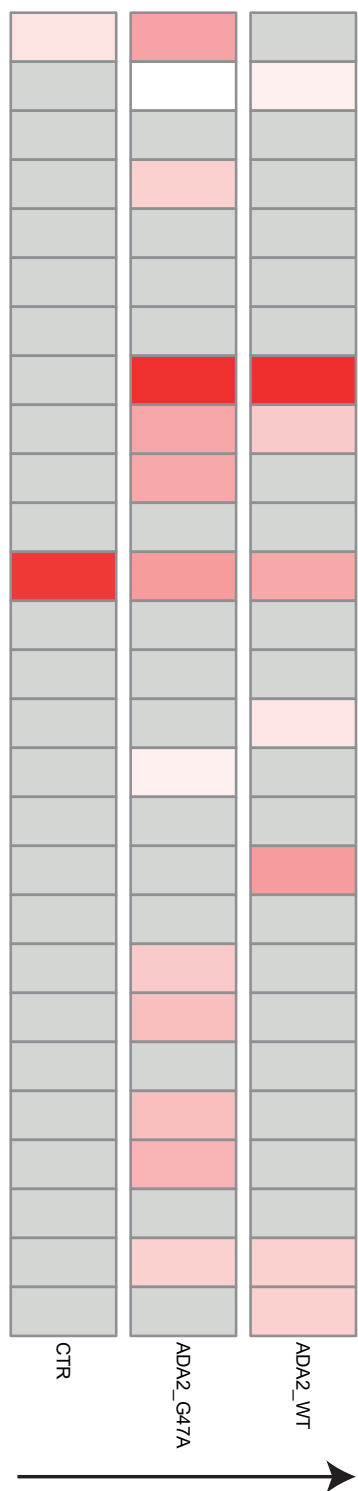

Order of Run
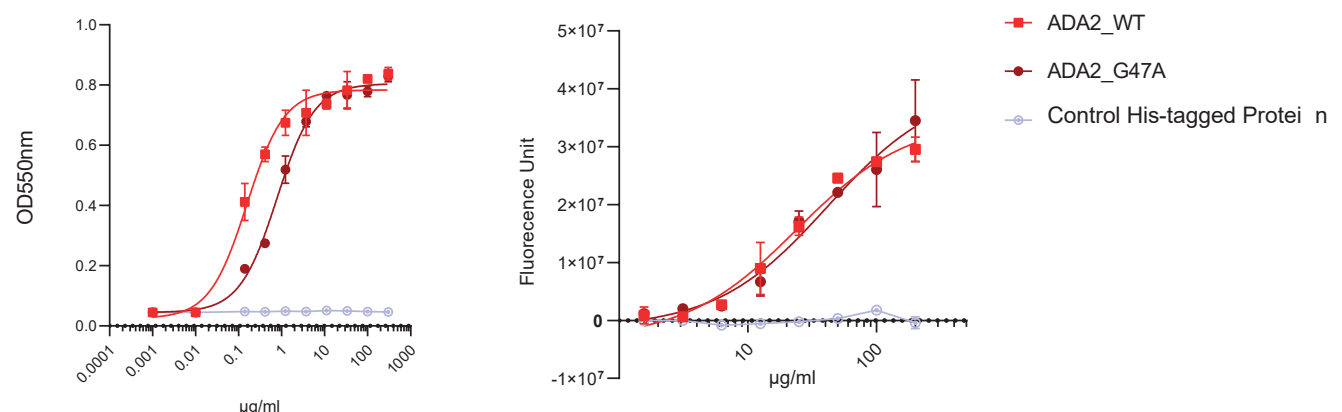

Run 3

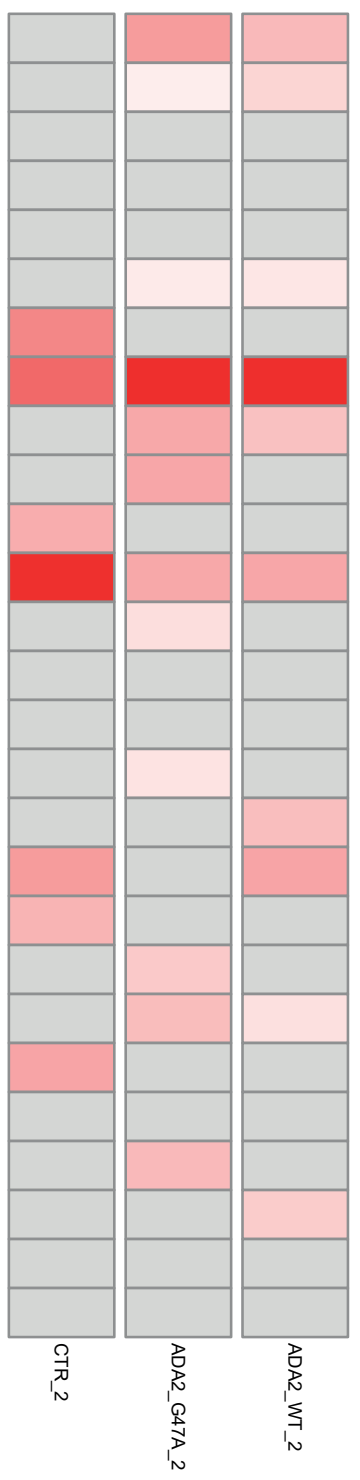

\section{Run 3}

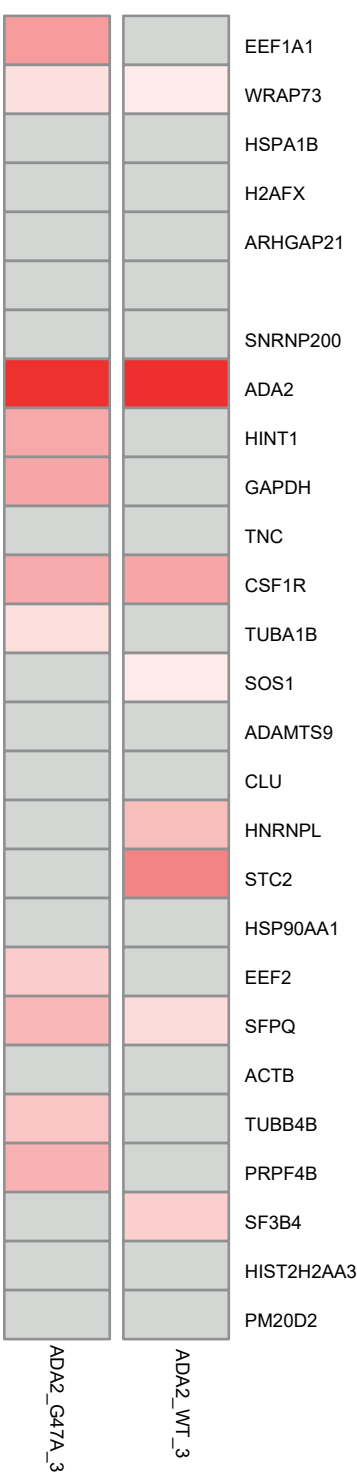

B

\section{B}

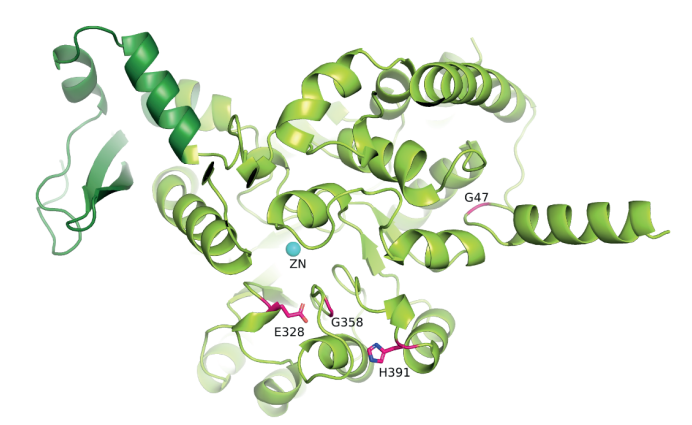

C
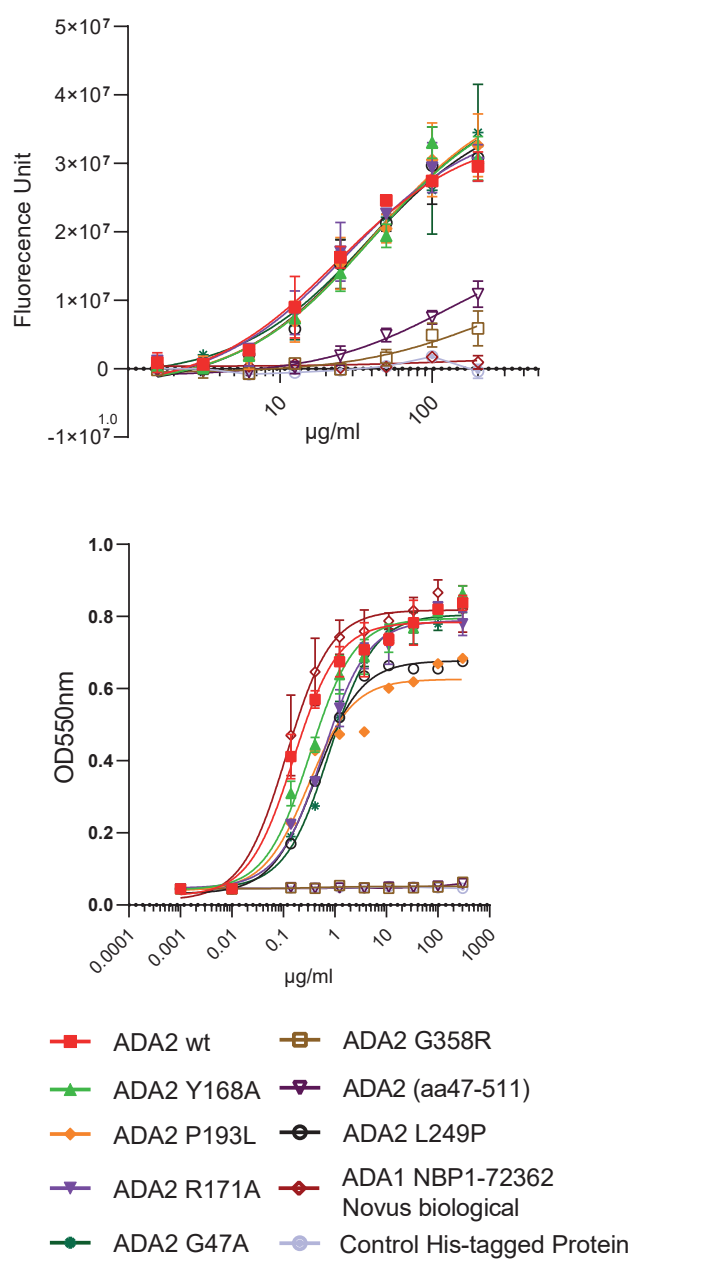